\title{
On the origins and conceptual frameworks of natural plasticity - lessons from single-cell models in C. elegans
}

Julien Lambert ${ }^{1}$, Carla Lloret-Fernández ${ }^{2}$, Lucie Laplane ${ }^{3}$, Richard J. Poole ${ }^{2, \#} \&$ Sophie Jarriault ${ }^{1}{ }^{1,}$

\begin{abstract}
AFFILIATIONS
1, IGBMC, Development \& Stem Cells Dept, CNRS UMR7104, INSERM U1258, Université de Strasbourg, 1 rue Laurent Fries, 67404 Illkirch CU Strasbourg, France

2, Department of Cell and Developmental Biology, University College London, Gower Street, London WC1E 6BT, United Kingdom
\end{abstract}

3, CNRS UMR 8590, University Paris I Panthéon-Sorbonne, IHPST, Paris, France

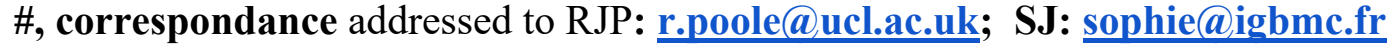

\section{ORCIDs:}

JL: 0000-0002-4667-8461

CLF: 0000-0002-5370-9318

LL: 0000-0003-0185-3323

RJP: 0000-0001-6414-2479

SJ: 0000-0003-2847-1675

Running title: Conceptual frameworks of natural plasticity

\section{Keywords:}

Reprogramming, Transdifferentiation, Cellular transition states, C. elegans, Developmental trajectory, Cellular plasticity, Waddington landscape, Transdetermination, Specification, Commitment, Determination, Differentiation 


\begin{abstract}
How flexible are cell identities? This problem has fascinated developmental biologists for several centuries and can be traced back to Abraham Trembley's pioneering manipulations of Hydra to test its regeneration abilities_in the 1700s. Since the cell theory in the mid-nineteenth century, developmental biology has been dominated by a single framework in which embryonic cells are committed to specific cell fates, progressively and irreversibly acquiring their differentiated identities. This hierarchical, unidirectional and irreversible view of cell identity has been challenged in the past decades through accumulative evidence that many cell types are more plastic than previously thought, even in intact organisms.

The paradigm shift introduced by such plasticity calls into question several other key traditional concepts, such as how to define a differentiated cell or more generally cellular identity, and has brought new concepts, such as distinct cellular states. In this review, we want to contribute to this representation by attempting to clarify the conceptual and theoretical frameworks of cell plasticity and identity. In the context of these new frameworks we describe here an atlas of natural plasticity of the cell identity in C. elegans, including our current understanding of the cellular and molecular mechanisms at play. The worm further provides interesting cases at the borderlines of cellular plasticity that highlight the conceptual challenges still ahead. We then discuss a set of future questions and perspectives arising from the studies of natural plasticity in the worm, that are shared with other reprogramming and plasticity events across phyla.
\end{abstract}

\title{
Part 1: Introduction
}

The study of cellular plasticity is the study of changes in cellular identities. In this section we will discuss the notion of cellular identity in the animal kingdom with an emphasis on the nematode Caenorhabditis elegans. We will start by discussing how to consensually define it, the conceptual steps describing its acquisition during development and what cellular plasticity entails (Fig. 1A). We will place particular focus on cellular plasticity events involving the swap of differentiated identities.

\section{1 - How to define cellular identity?}


Historically, cell types have been identified on the basis of their morphology, location, function and where possible, cell lineage. In the last 40 years, the focus moved first towards using molecular markers, notably through in vivo visualisation using fluorescent fusion constructs (Chalfie et al., 1994; Hobert, 2016; Lippincott-Schwartz and Patterson, 2003), and more recently to RNAseq and scRNAseq approaches that refine individual cellular identities more comprehensively (Brackston et al., 2018; Dunn et al., 2014; Mikkelsen et al., 2008; Packer et al., 2019; Taylor et al., 2019; Treutlein et al., 2016). Today two criteria are primarily used to assign cellular identities. The first one is cellular history (lineage history) but the ability to use this criterion depends on the lineage-tracing tool box in each model system. In C. elegans this lineage is fully elucidated and stereotyped (see Box 1), providing an unparalleled degree of precision that allows single-cell resolution analysis and the possibility to consider each cell as unique. The second criterion is the phenome: the combination of all the phenotypic traits of a cell. This includes the localisation of the cell within a tissue, its morphology, its function (if known), and the expression of specific batteries of genes and proteins. Importantly, it should be noted that protein activity will better reflect a cellular identity than the transcriptional regulation of the protein-coding genes.

Recently, an alternative way of defining cellular types beyond specific markers and lineages, has been proposed (Arendt et al., 2016). Briefly, the different cell types, which here are equated to cellular identities, express distinct and unique gene expression programs including specific molecular effectors to fulfil the cell's distinct function. In any considered cell type, the vast majority of these expressed genes is controlled by a small number of transcription factors, and the network is shaped by feedback loops to maintain the expression program. Therefore, the architecture and the core elements, called Core Regulatory Complexes (CoRC), of such regulatory mechanisms define a signature (Arendt et al., 2016) specific of a given cell type. Arendt and colleagues therefore propose to define cell types as collections of cells that display the same specific regulatory mechanisms. Importantly, this framework implies that cells with different phenotypes and different functions (however similar) in different organisms, fall into the same cell type if they display the same signature, such as the visceral muscle in vertebrates (smooth) and in D. melanogaster (striated). Thus, cell types can share an evolutionary lineage but not necessarily a developmental lineage. However, using such classification requires the knowledge of the CoRC, something that is not accessible for many cell types.

As previously mentioned, the transparency of $C$. elegans and its stereotyped lineages allows the identification of individual cells. Cell identity can therefore be extended beyond broad cell types and even specific subtypes in such a way that identity can be specific to a single cell in a whole organism. In this review we will therefore extensively use cellular lineages to define individual cellular identities. 
For instance, the PDA neuron falls into the neuronal type and cholinergic motor neuron subtype (Pereira et al., 2015a; White et al., 1986) but its individual identity is "PDA": there is only one such neuron in the worm with its unique cell position, connectivity, expression program and specific signature.

The use of more modern molecular techniques to evaluate cell identity has also revealed the existence of heterogeneity in isogenic cell populations, suggesting that cells exist in different "cell states", for example in response to their environment, developmental condition, cell cycle status or stochastic gene expression. Thus, within a cell identity, minor and dynamic variations in some of these criteria can be tolerated, but not to the extent where its function would be modified. It can thus be argued that these cell states represent the "variation space" or "state space" (Huang, 2010), within which a given cell exhibits a defined and stable identity (Fig. 1B). Immune T-cell activation in mammals illustrates this: while displaying canonical T-cell markers, they exist in different activated states - meaning that each activated T-cell, while performing a similar function, recognises a different antigen in response to the diversity of stimuli that the immune system faces - and all of these states coexist within the generic T-cell identity (Morris, 2019; Zemmour et al., 2018). Such stable "variation states" can be contrasted with the transient cell states that can be observed during transitions between cell identities, and which we will call "transition states" (see section 1.6.5). While the concept of cell states and their relevance to define identities is debated, many take them into account when defining cellular identities (Morris, 2019).

\section{2 - How to define "differentiated"?}

Using the criteria defined above, all cells can be considered to have an identity, be they undifferentiated embryonic blastomeres or differentiated skeletal muscle cells. When embryonic blastomeres and skeletal muscle cells are considered, both have a function, display key characteristics such as specific behaviour and morphology, and express specific molecules that ensure their function, defining their distinct cellular identities. A key difference between the two is that skeletal muscle cells represent an end-of-lineage. Therefore, we will define differentiated cells as cells that fulfill a specific function and that are situated at the end of a lineage; of note, proliferation will not be considered a function. Importantly, some cells that meet all the criteria of a differentiated cell and represent an end-of-lineage can proliferate (e.g., hepatocytes). Thus, a cell that would be classically defined as differentiated can yet retain proliferative capability.

\section{3 - Cellular plasticity}


During development of multicellular organisms, specialised cells arise from the zygote, an initial totipotent and undifferentiated cell, and acquire their identity through blastomere specification, commitment and differentiation (Box 2, Fig. 1A). Cellular plasticity represents the ability of a cell, at any stage, to adopt, or generate a daughter of, another identity. This definition encompasses various types of transitions (changes of cellular identity), between undifferentiated identities, between undifferentiated and differentiated identities, but also between differentiated identities (Fig. 1A).

\section{4 - Paradigm shift: from irreversible entities to flexible identities}

Since the differentiated identity is usually stable and safeguarded through various molecular mechanisms (this review, (Brumbaugh et al., 2019; Holmberg and Perlmann, 2012; Merrell and Stanger, 2016)) it was first thought to be both irreversible and unidirectional (from the unspecialised towards the specialised and fixed). This hierarchical paradigm was supported by early experiments in embryology (Weiss, 1973; Wilson, 1906), haematology (Doan, 1939). However, the flexibility of differentiated identities was highlighted early in alternative developmental model (Koizumi and Bode, 1991, 1986; Zwilling, 1963) and can even be traced back to works on the freshwater hydra Chlorohydra viridissima regeneration by Abraham Trembley in the mid seventeenth century. The first use of word plastic to describe changes in cell identity dates from the late nineteenth century and Rudolf Virchow (Virchow, 1886), who called "plastic processes" the acquisition of unusual cellular phenotypes in response to a lesion.

Plasticity of the differentiated identity, described in many natural settings, remained controversial for a long time. It was not before it could be reproduced in vitro that it became more widely embraced. Four series of studies aimed at inducing plasticity were especially prominent in reinvigorating the ideas of plasticity and led to a paradigm shift (reviewed further in (Kraft and Rubin, 2016)).

First, John Gurdon demonstrated that the transplantation of specialised nuclei into enucleated oocytes of Xenopus laevis results in the proper development of a fully developed animal (Gurdon, 1967, 1962). Earlier nuclear transplantation in enucleated oocytes of Rana pipiens (King and Briggs, 1955) also highlighted that the efficiency of such reprogramming decreased with the developmental stage of the transplanted nuclei. In a similar fashion, Miller and Ruddle (Miller and Ruddle, 1976) demonstrated that differentiated murine thymocytes could be de-differentiated into a pluripotent hybrid when fused with pluripotent teratocarcinoma cells. Thus, differentiated nuclei (and cells) can be converted into pluripotent cells when placed in the proper environment. 
Secondly Blau performed fusion experiments of differentiated cells with myoblasts which demonstrated that differentiated cells can be reprogrammed directly without a de-differentiation into a pluripotent cell (Blau et al., 1985). Importantly, she repurposed the use of the term 'plasticity' to describe the ability of the differentiated nuclei to change their identity based on their intrinsic environment.

Thirdly, Weintraub and colleagues demonstrated that over-expression of the sole myogenic differentiation factor MyoD, a transcription factor, in fibroblasts or adipocytes was sufficient to convert these cells into myogenic cells (Weintraub et al., 1991).

Finally, the discovery of induced Pluripotent Stem Cells (iPSCs) by Takahashi and Yamanaka using four transcription factors (TFs): OCT4, SOX2, KLF4 and c-MYC (Takahashi et al., 2007; Takahashi and Yamanaka, 2006) brought plasticity right back into the limelight, reinvigorating the field to booming proportions. Today numerous groups induce differentiated cell identity conversions using the same TF-based logic but without inducing a transition through a pluripotent cell, usually referred to as direct reprogramming.

As natural plasticity is the main focus of this review, we should emphasise that while this shift in paradigm took decades to be widely accepted, many beautiful studies in a variety of models from invertebrates to vertebrates pointed all along to the plasticity of the differentiated identity in nature (this review, (Brockes and Kumar, 2002; Li et al., 2005)).

\section{5 - Various forms of cellular plasticity}

\subsection{1 - Classical cell types naturally expressing cellular plasticity}

A key aspect in communicating scientific results and concepts is define what they entail for each author (Mills et al., 2019). Our definition of cellular plasticity encompasses cells that naturally display an ability to change their identity, which are the following:

Blastomeres and progenitors: The first challenge that an organism faces is to develop from a single cell to a mature, coherent and integrated individual that can contain from very few to thousands of specialised cell types. Therefore, blastomeres, the cells that arise from the first zygotic divisions, inherently exhibit cellular plasticity. Their cellular potential (Box 3) is progressively restricted during development. Along the same lines, progenitors, the cell intermediates between early blastomere or stem cells and differentiated cells in a lineage, also display cellular plasticity as their role is to give rise to various cell types. Of note, embryonic stem (ES) cells are derived from blastomeres that form the inner cell mass of vertebrate embryos and are thought to retain this developmental pluripotent 
state. Lineages from all three embryonic layers, including germ cells, can be derived from ES cells (Ding et al., 2016; Shparberg et al., 2019; Vazin and Freed, 2010). Since there are no ES cell lines derived from $C$. elegans, this topic will not be addressed in this review, but we recommend (Huang et al., 2015) and (Eguizabal et al., 2019).

Tissue stem cells: Cells with stem cell properties are readily found in vivo in mature tissues of vertebrates and insects (Gehart and Clevers, 2019; Moss and Leblond, 1971; Yin et al., 2013). They are unipotent or multipotent - meaning that they can give rise to only one or a few cell types (Box 3). Tissue stem cells, also called somatic or adult stem cells, typically exhibit two types of cellular division: they can either symmetrically divide to generate two stem cells or two differentiating daughters - or divide asymmetrically, giving rise to one progenitor or differentiated cell and one stem cell. Since they provide tissues with newly differentiated cells, the control of the stem cell divisions is critical for tissue homeostasis. In C. elegans, only the germline can be considered as a long-term stem cell pool (Albert Hubbard and Schedl, 2019).

\subsection{2 - Unexpected cellular plasticity achieved through natural \& induced reprogramming}

Differentiated identities can be changed, or reprogrammed, either naturally - during development or in response to damage - or artificially. The latter case includes reprogramming to a pluripotent state as well to any other cell identity.

Retro-differentiation, de-differentiation and pluripotent reprogramming: Retro-differentiation, de-differentiation and pluripotent reprogramming represent processes where cells lose their differentiated characteristics, sometimes also acquiring a higher cellular potential in the process. Retro-differentiation implies the return to an earlier identity in the same lineage (e.g: hepatocyte progenitor generation from differentiated hepatocytes in response to chronic injury (Tarlow et al., 2014)), de-differentiation implies only the loss of differentiated properties. Pluripotent reprogramming is the induced conversion from a more differentiated cell into a pluripotent stem-cell like state as pioneered by (Takahashi and Yamanaka, 2006).

Transdetermination: Transdetermination corresponds to the swap of a cell that is determined to produce a certain set of cell types into a cell determined to give rise to another set of cell types. It has been mostly studied during the development of the imaginal wing disc of Drosophila melanogaster (Maves and Schubiger, 1995; Shearn et al., 1978; Worley et al., 2012) but has also been described in neurogenesis and haematopoeisis (Bjornson et al., 1999; Ferrari et al., 1998; Pereira et al., 1995). The difference between transdetermination and transdifferentiation (see below) mostly relies on describing a cell as determined or differentiated respectively. 
Transdifferentiation: Transdifferentiation (Eguchi, Goro; Kodama, 1993; Selman and Kafatos, 1974) or direct reprogramming, is the process through which a cell switches from one differentiated cell identity into another differentiated cell identity. A transdifferentiation event must fulfill two criteria: i) the two differentiated cell identities (before and after the switch) must be clearly defined; and ii) the direct cell lineage relationship between these two cell identities needs to be unambiguously established. This implies that the reprogramming process does not occur through a succession of stable progenitor identities. Additionally, it has been proposed that the final cellular identity is expected to be stable and the process irreversible (Okada, 1991). First highlighted by work in labial glands of Antheraea polyphemus (Selman and Kafatos, 1974) and newt lens regeneration (Eguchi et al., 1974; Henry and Tsonis, 2010; Kodama and Eguchi, 1995; Yamada, 1977), transdifferentiation can occur in different contexts: induced, pathogenic, regeneration and natural development. During regeneration, transdifferentiation is observed in various models including mouse liver (Yanger et al., 2013) and adipocytes (Plikus et al., 2017), zebrafish heart (Zhang et al., 2013) or brain (Kroehne et al., 2011), or mammalian lung (Logan and Desai, 2015) and the enteric nervous system (Laranjeira et al., 2011; McCallum et al., 2020). However, transdifferentiation is not always triggered by an external stimulus and has been shown to naturally occur, for instance in the pancreas (Means et al., 2005) and during development of coronary arteries (Red-Horse et al., 2010). Various events of both natural and induced transdifferentiation have been described in C. elegans (Jarriault et al., 2008; Molina-García et al., 2020; Riddle et al., 2013; Sammut et al., 2015; Tursun et al., 2011; Zhu et al., 1998) (see (Rothman and Jarriault, 2019) for a full list), notably taking advantage of the described lineage and the high cellular resolution that the worm allows for (see Part 2). In addition, induced transdifferentiation using cell-fate determinant TFs (reviewed in (Srivastava and DeWitt, 2016)) have successfully reprogrammed pre-B cells to macrophages (Di Tullio et al., 2011; Rodríguez-Ubreva et al., 2012), or fibroblasts into cardiomyocytes (Efe et al., 2011; Ieda et al., 2010; Kapoor et al., 2013; Qian et al., 2012; Song et al., 2020; Zhou et al., 2016), hepatocytes (Song et al., 2016), and neurons (Guo et al., 2014; Heinrich et al., 2010; Karow et al., 2012; Vierbuchen et al., 2010). Transition through pluripotency during transdifferentiation appears to be an event-specific exception: a transient pluripotent state was only observed when pluripotent TFs were used in the inducing mix (Maza et al., 2015), while several studies demonstrated that no pluripotent state occurs during reprogramming (Di Tullio et al., 2011; Kurian et al., 2013; Richard et al., 2011).

\section{6 - Frameworks for the study of cellular plasticity}

\subsection{1 - The Waddington epigenetic landscape}


The Waddington epigenetic landscape, depicted as a ball representing a cell rolling down valleys towards final cellular identities, has shaped how cellular differentiation and cellular plasticity were envisioned (Fig. 2A). In this section, we will cover how the concept of the epigenetic landscape was originally envisioned and how it has been re-interpreted in the era of single-cell transcriptomics and computational biology, as well as the insights it brings for the study of plasticity.

Waddington developed a series of theories to fill major gaps of the Neo-darwinian Evolutionary Theory. Notably, how does a single genotype produce all the cell types that are needed for mature organisms? In the Waddington landscape cells follow developmental trajectories from pluripotent cells (at the top of the diagram), to differentiated cells (at the bottom) and, at some points during development, face choices that allow for cellular specialisation (Allen, 2015; Waddington, 1957). Importantly, differentiated identities constitute the attractors of the landscape: the most stable positions from which a cell cannot escape. Waddington used the term epigenetics, the mechanisms modulating the expression of genes (not in the modern sense of reversible modification of the chromatin), to define the shaping force of the landscape. Gene regulatory networks (GRNs), notably through the work of Kauffman, Davidson and Huang (Britten and Davidson, 1969; Huang et al., 2005; Kauffman, 1992, 1969) were later identified as the underlying mechanism. It is the specialisation of the GRN in each lineage that drives cellular specialisation from pluripotent cells with high potentials (at the top of the diagram), to differentiated cells with lower potentials (at the bottom). GRNs are in more stable configurations (they do not change much over time) in differentiated identities than in any other state during differentiation (Brackston et al., 2018; Huang et al., 2005; Wang et al., 2010; $\mathrm{Xu}$ et al., 2014). Therefore, developmental trajectories converge towards these differentiated attractors. Of note, the notion of stable GRN configurations in differentiated cell types meets the proposed regulatory signature that maintains stable and specific gene expression developed by Arendt and colleagues (Arendt et al., 2016): in differentiated cell types, specific CoRC and their regulatory interactions define the configuration of the GRN, ensuring the stability of gene expression.

The rise of RNA-seq and computational biology in the last two decades has reinforced the use of the epigenetic landscape. Sampling enough individual cells gives the relative occupancy probability of every point of the transcriptional space, therefore unraveling the shape of the landscape (Marr et al., 2016). Waddington-like landscapes have been built in the context of different developmental models such as T-cell differentiation (Rebhahn et al., 2014), pancreatic fate decisions (Zhou et al., 2011) or development of C. elegans vulva (Corson and Siggia, 2012).

The Waddington epigenetic landscape provides a powerful framework for understanding how cellular identities are acquired during development. At the transcriptional level it links gene expression 
patterns to developmental trajectories, and it allows the use of mathematical formalism and computational modelling to describe acquisitions of identity.

\subsection{2 - Limitations of the Waddington epigenetic landscape to display reprogrammed identities}

Waddington published his theories in the 1950's, when the prevalent paradigm posited that cellular identities were irreversible, iPSCs undiscovered and transdifferentiation poorly documented. The original epigenetic landscape focuses on development and so fails to represent all the cell types and paths that arise during reprogramming. Notably, iPSC generation from differentiated cells is often represented as a backward path on the landscape. However, iPSC reprogramming is unlikely to occur through revisiting backward developmental intermediates (Hansson et al., 2012; Polo et al., 2012; Wang et al., 2011) and they represent a distinct stable cell identity. Similarly, direct reprogramming of one cell type into another also follows alternative paths.

\subsection{3 - Development: Step-and-Go or Smooth-Drifting?}

In the Waddington landscape, only the differentiated state is depicted as an attractor. However, development is classically understood as the succession of intermediates that lead to the generation of differentiated identities. Importantly, these intermediates are stable enough to be observed in vivo and even kept in culture if placed in the appropriate conditions. This unravels the existence of additional attractors in developmental trajectories. For example, tissue stem cells constitute a distinct and stable identity, characterised by a specific, stable, configuration of the GRN. That configuration allows a relative stability in gene expression, and proper functioning of the tissue stem cell. Upon receiving the right signals, they change their identity to a differentiated one. In other words, their GRN undergoes a re-configuration. Development is therefore understood as a step-and-go process: distinct local attractors and sharp transitions in between (Ferrell, 2012) (Fig. 2B).

However, it can be argued that the intermediates observed during development are not distinct one from another but rather constitute a continuum. This view is actually similar to what is depicted in Waddington original landscape and the GRN undergoes a continuous reconfiguration (smoothdrifting) until the differentiated state is reached. That paradigm has gained interest in the haematology field over the past few years (reviewed in (Laurenti and Göttgens, 2018)). Importantly, Velten and colleagues (Velten et al., 2017) have proposed that the early haematopoiesis was a continuum rather than a collection of distinct progenitors based on sc-RNAseq. 
How to decipher between these two models? An ideal test would be to assess the stability of the GRN configuration for the different intermediates of a given developmental model. However, this can be very challenging, since it requires the identification of the core elements of the GRN configuration in the intermediates, and an evaluation of the stability of their expression.

The use of scRNA-seq data and the reconstitution of developmental trajectories - achieved by Packer and colleagues (Packer et al., 2019) for the embryonic development of C. elegans - may not allow the two models to be distinguished. Indeed, besides the ability to reach the needed sampling granularity in a given time frame, the distances between cell clusters represented in dimensionality reduction displays can depend on the parameters. Therefore, apparently discontinuous trajectories that would support a step-and-go model may not reflect two distinct attractors separated by a sharp transition. On the other hand, continuities such as depicted in (Velten et al., 2017) could result from the fact that the distinct signatures of the different identities are too close to be detected with the current methods. For instance, the share of housekeeping genes (whose expression is not affected by the configuration of the GRN) in their transcriptome can be larger in undifferentiated cell types than for differentiated cells (Laurenti and Göttgens, 2018) and mask the distinct signatures.

\subsection{4 - Modern epigenetic landscapes and the modelling of cellular plasticity}

Current models of epigenetic landscapes (reviewed in (Brackston et al., 2018; Huang, 2012; Morris et al., 2014; $\mathrm{Xu}$ et al., 2014)) understand cellular identities as specific configurations of the GRN; i.e. attractors. The core components of the GRN as well as their regulatory interactions are encoded into a number of differential equations that together describe the behaviour of the network. It is possible to calculate the potential of the system for a given location on the multi-dimensional space (Brackston et al., 2018; Wang et al., 2010; Xu et al., 2014), and construct a landscape bin concatenating the local values of the potential. Importantly, both the differentiated and the multipotent state constitute local minima (Fig. 2B); i.e. the dominating attractor for a specific region on the landscape (Brackston et al., 2018; Li and Wang, 2013; Mojtahedi et al., 2016; Wang et al., 2010; Xu et al., 2014).

The pluripotent state is associated with high variability and dynamism in gene expression (reviewed in (MacArthur and Lemischka, 2013)), which translates into higher instability on the epigenetic landscape, and has been well documented for the pluripotency factor Nanog (Abranches et al., 2014; Chambers et al., 2007; Kalmar et al., 2009; MacArthur et al., 2012; Miyanari and TorresPadilla, 2012). The differentiated state, considered more homogeneous in expression, is modelled to exhibit lower potential/greater stability (visually deeper) than the undifferentiated state (shallow) 
(Brackston et al., 2018; Li and Wang, 2013; Xu et al., 2014) (Fig. 2B). This explains the directionality of differentiation from less stable to more stable. Although isolated, it is important to point out that opposite observations have also been reported. During axolotl limb regeneration, the population of multipotent reprogrammed cells is more homogeneous than the initial and final differentiated population (Gerber et al., 2018).

During differentiation, the pluripotent attractor exhibits low stability. Therefore, individual cells can explore their surroundings and tend to converge towards the differentiated attractors. Since these ones are more stable, cells do not escape. Importantly, the pluripotent reprogramming of a differentiated identity, for example through the overexpression of pluripotency transcription factors would result in the destabilisation of the differentiated attractor and stabilisation of the pluripotent one. The cell will therefore converge towards the pluripotent attractor. In a similar manner, transitions between differentiated identities can be explained by the destabilisation of the initial attractor by overexpression of specific transcription factors (induced transdifferentiation), by developmental signals (natural transdifferentiation) or by a lesion (regeneration).

\subsection{5 - Transition states}

Another key insight arising from modelling studies concerns the transition state (TS). Although the transition state can be defined as any state between two defined identities (MacLean et al., 2018), we will restrict our analysis to the collection of states exhibited during a plasticity event. Two distinct types of transition states can be predicted to arise during reprogramming: non-stable and metastable. A non-stable TS is normally defined at the population level as a continuous collection of heterogeneous cells transitioning from an attractor to another (Fig. 2C,D) (Brackston et al., 2018; Moris et al., 2016). This type of TS has been used for instance to describe haematopoietic differentiation (Moris et al., 2016; Pina et al., 2012). At the transcriptomic level, the specific gene expression pattern of the initial identity is progressively switched off while the specific gene expression pattern of final identity is switched on (Fig. 2E).

Meta-stable transition states, on the other hand, are described at the single cell level. These can be viewed as a minor attractor between two larger ones (Fig. 2F,G) (Li and Wang, 2013). In an elegant modelling study, $\mathrm{Xu}$ and colleagues investigated the link between the nature of the TS and the mutual inhibitions between the GRN configurations of the considered differentiated identities $(\mathrm{Xu}$ et al., 2014). A meta-stable TS arises when mutual inhibition between the two identities is relatively strong. For low inhibitions, the predicted TS would rather resemble non-stable TS. For very strong 
mutual inhibition, direct reprogramming is predicted to be impossible and any transition between the differentiated identities has to occur through a pluripotent identity.

Meta-stable transition states can be divided in two subtypes depending on their phenotypes (MacLean et al., 2018). The first subtype would be a mixed identity (Fig. 2H.i), as a bridge between the major attractors, where gene expression specific to the initial and final identity coexist. The other subtype would be a distinct identity between the major attractors. In this case, the TS possesses its own different gene expression pattern (Fig. 2H.ii). A prominent question is whether such distinct meta-stable TS generated during reprogramming recapitulate the intermediate identities observed during development. Some fibroblast-to-neuron direct reprogramming studies suggest that they could bear some similarity to the neuronal progenitors encountered during classical neurogenesis (Karow et al., 2018; Treutlein et al., 2016). However, how close these intermediates and neuronal progenitors are is still unclear. Notably, during fibroblast-to-neurons direct reprogramming, Treutlein and colleagues demonstrated that some, but by large not all neural progenitor genes, are expressed during a transition state distinct from both final and initial identity. By contrast, during Ambystoma mexicanum limb regeneration, reprogrammed cells first transition through a state that is distinct from the progenitors encountered during development, before converging towards a limb bud progenitor identity (Gerber et al., 2018).

\section{Part 2: An atlas of cellular plasticity in the worm}

\section{1 - Decreasing plasticity during embryonic developmental progression}

During early development embryonic blastomeres are thought to lose cellular potential as they proliferate and cells acquire their final differentiated identities. However, as discussed in Part 1, whether this progression is smooth or punctuated remains unclear. Can the moments of specification, commitment and differentiation be identified in C. elegans and, if so, then what are the molecular correlates? How plastic are embryonic blastomeres and when during development is this plasticity lost?

\subsection{1 - Early embryonic blastomeres are intrinsically plastic}

One cell stage C. elegans embryos are by definition pluripotent, yet the determinate nature of the C. elegans lineage combined with 50 years of work on other nematodes by zur Strassen (Hyman, 1960; zur Strassen, 1896) suggested a rigid developmental programme with little plasticity. Early 
ablations of individual blastomeres and blastomere fusion experiments initially supported the view that C. elegans development was cell-intrinsically specified (Junkersdorf and Schierenberg, 1992; Schierenberg, 1984; Stevens, 1909; Sulston et al., 1983). Moreover the culture of isolated founder blastomeres suggested that they generate largely the same tissue types as they do in an intact embryo (Laufer et al., 1980; Priess and Thomson, 1987) Several years of subsequent investigations, including beautiful maternal-effect lethal forward genetic screens (Kemphues et al., 1988) and lineage-based genetic screens (Horvitz and Sulston, 1980) have revealed a number of asymmetrically inherited/expressed factors that fit this idea of intrinsic development (reviewed in (Bertrand and Hobert, 2010; Mizumoto and Sawa, 2007; Phillips and Kimble, 2009; Rose and Gonczy, 2014)).

However, it is now clear that early blastomeres are not only specified in a cell-intrinsic manner but require cell-signalling events to drive alternative fates and are much more plastic than originally thought. Elegant blastomere manipulation experiments and the examination of genetic mutants have provided evidence for several non-autonomous signalling interactions involving predominantly the Notch- and Wnt-signalling pathways between early blastomeres (reviewed in (Priess, 2005; Sawa and Korswagen, 2013)). More recently, the plasticity of embryonic blastomeres has been tested through forced expression of key transcriptional regulators of differentiated tissues, converting these embryonic blastomeres into endodermal, mesodermal and ectodermal cell types (reviewed in (Spickard et al., 2018)). Taken altogether, these results suggest that the early blastomeres of $C$. elegans are multipotent and can be redirected into a broad array of cell types.

\subsection{2 - Timing and molecular nature of determination}

Although early blastomeres remain plastic and can be converted to other fates, several lines of evidence indicate a loss of plasticity and commitment to specific cell types by late embryonic and early larval stages. Most notably, over-expression of the same transcription factors that re-specify early blastomeres has little to no effect when performed at late embryogenesis, larval or adult stages (Coraggio et al., 2019; Fukushige and Krause, 2005; Gilleard and McGhee, 2001; Horner et al., 1998; Patel and Hobert, 2017; Richard et al., 2011; Zhu et al., 1998). Carefully staged over-expression has revealed one multipotency-to-commitment (MCT) transition, which occurs at 250 mins of embryo development (Yuzyuk et al., 2009), when most lineages still have one or two more divisions before terminal differentiation. Molecularly, this reduction in plasticity depends on H3K27me3 and H3K9me3 chromatin compaction and Notch signalling (Djabrayan et al., 2012; Patel and Hobert, 2017; Yuzyuk et al., 2009). However, it is important to note that the occurrence of the embryonic MCT identified above does not imply that cells are yet fully committed to their terminal identities, for instance, cell-cell interactions can distinguish between equivalent fates at later stages (Sulston et 
al., 1983). Moreover, neuronal subtype identities are specified by Wnt-signalling during their terminal divisions (Kaur et al., 2020) and there is a particularly intriguing example of a progenitor that gives rise to a muscle and a neuron at its terminal division (Luo and Horvitz, 2017), suggesting broad plasticity of the mother or cell type conversion of a daughter (Fig. 3B). Lastly, over-expression of single TFs in larva and adult are still capable of transforming certain cell types suggesting some cells continue to display latent plasticity post-mitotically (Jin et al., 1994; Patel and Hobert, 2017; Riddle et al., 2016, 2013; Sallee et al., 2017). An extraordinary case of latent plasticity is exhibited by the germline, where highly specialised gametes, upon fertilisation, generate a zygote capable of producing a complete organism generation after generation. To read further on the differences between somatic and germline mechanisms of plasticity we recommend (Kelly, 2014) and (Rothman and Jarriault, 2019).

Taken together, the finding described above suggests that there is a progressive loss of plasticity during embryonic development, with most somatic cells unambiguously committed to their final identities by the end of gastrulation at $\sim 450$ mins. Intriguingly, however, a number of cells that are born during embryogenesis later undergo natural transdifferentiation. This is the focus of the next sections.

\section{2 - Naturally plastic cells, cellular steps and transition states}

Despite the evidence of a decrease in cellular potential during the transition from specification to determination, and of the stable differentiated identities in development, a close look into the somatic lineage of the worm (Horvitz and Sulston, 1980; Sulston and Horvitz, 1977) already suggests that some cells may change identities, based on their appearance under the light microscope. This has led to the first demonstration that transdifferentiation can occur naturally in the worm (Jarriault et al., 2008). Over the last few years, more of these identity switching cells included in the worm lineage have been characterised, and some unexpected ones have been discovered (collected in Fig. 3A).

\subsection{1 - Transdifferentiation in the absence of cell division - cellular paradigms}

The $\mathbf{Y}$ cell is one of the six epithelial cells that form the first larval stage (L1) rectum. These rectal cells are born in the embryo 300 min after fertilisation (Sulston et al., 1983) and, with the exception of $\mathrm{Y}$ and $\mathrm{K}$, remain as rectal cells in hermaphrodites throughout the life of the animal. However, at late L1 Y retracts from the rectum, migrates away, and transforms into the PDA motoneuron that has an as yet unknown function (Jarriault et al., 2008; White et al., 1986) (Fig. 4A). A combination of light and electron microscopy imaging, together with the analysis of the molecular markers expressed, 
showed that $\mathrm{Y}$ and PDA represent two distinct cellular identities. This was the first well-characterised example of transdifferentiation in the worm (Jarriault et al., 2008; Sulston and Horvitz, 1977) and it occurs without a division.

The bilateral pair of PHso1 socket glial cells form part of a sensory organ called the phasmid sensillum (Altun and Hall, 2010). Socket glial cells form a pore in the cuticle through which the dendrites of sensory neurons contact the environment. In the tail of the worm, there are two socket glial cells: PHso1 and PHso2. During early larval stages PHso1 forms the primary pore in both sexes but, in adult males, PHso2 takes over to form the main pore (Sulston et al., 1980). Recently, the male PHsol cells have been described to undergo a glia-to-neuron cell identity switch during sexual maturation to produce the PHD putative proprioceptor neurons (Fig. 4B), which are involved in a male-specific readjustment movement during mating. As with Y and PDA, based on morphology, molecular markers and function, PHsol and PHD unequivocally represent two distinct and specialised cellular identities (Molina-García et al., 2020).

\subsection{2 - Transdifferentiation in the absence of cell division - molecular details}

Genetic studies enabled the identification of many of the molecules involved (Fig. 4). Initiation of Y transdifferentiation and erasure of its epithelial identity requires the conserved NODE (Nanog and Oct4-associated deacetylase)-like complex composed of SEM-4/Sall, CEH-6/Oct and EGL-27/Mta, along with SOX-2/Sox activity, acting upstream of the Hox transcription factor EGL-5 (Jarriault et al., 2008; Kagias et al., 2012). More recently, the ZTF-11/Myt1 transcription factor has been also implicated in the initiation step (Lee et al., 2019). The re-differentiation step into the PDA neuron requires the UNC-3/EBF transcription factor (Richard et al., 2011) likely acting as a terminal selector (Hobert, 2008). The SET-1 histone methyltransferase complex and the demethylase JMJD-3.1/Jmjd3.1 ensure the robustness of the transdifferentiation (Fig. 4A)(Zuryn et al., 2014).

Less is known so far about the molecules involved in PHso1-to-PHD (Fig. 4B). This male-specific cell identity switch is under cell-autonomous control of the sex-determination pathway (MolinaGarcía et al., 2020). Interestingly, some of the factors involved in Y-to-PDA (SEM-4 and SOX-2) are dispensable for PHso1-to-PHD, indicating that the mechanisms involved in natural transdifferentiation can vary between different events (Molina-García et al., 2020). The preoneuronal bHLH transcription factor HLH-14/Ascl1 is transiently expressed in PHsol during the cell remodelling, and is required for neuronal cell fate acquisition (M. Sammut, C. Lloret, R. P.oole, unpublished) 


\subsection{3 - Steps in cell state transition}

Single cell studies of the Y-to-PDA and PHso1-to-PHD transdifferentiations have unravelled the cellular and molecular steps involved. In PHso1-to-PHD, socket retraction is observed at the early L4 stage and is accompanied by the gradual downregulation of glial markers and the concomitant upregulation of neuronal markers (Molina-García et al., 2020), which is possibly suggestive of a mixed intermediate (Fig. 2E, Hi).

The visible initiation of the $\mathrm{Y}$ identity switch, when $\mathrm{Y}$ retracts from the rectum, involves the complete erasure of the initial rectal identity (de-differentiation). This results in an intermediate state (termed Y.0) that is devoid of epithelial and neuronal transgenic markers and of any defined morphological characteristics. A second intermediate (Y.1) then activates an initial neuronal program, without displaying a neuronal morphology, which is completed in the last UNC-3dependent step (Richard et al., 2011). The ability to identify Y.1 as a stable intermediate in mutant animals is suggestive of its existence as metastable transition state (Fig. 2Hii) and of a step-and-go process. The tools currently in use only suggest the existence of such states and characterisation of the transcriptional dynamics of these cells is required for a proper study of the putative transition states. In addition, the requirement of the proneural gene hlh-14 in PHso-1-to-PHD and the transcription factor $u n c-3$ in Y-to-PDA suggests that the activation of the neuronal programme uses mechanisms common to developmental differentiation. These putative cell state transitions are reminiscent of observations in mammalian cells where transition through a distinct state (Gerber et al., 2018) or activation of "switch genes" (Karow et al., 2018) is followed by transition through a developmental progenitor-like state (Gerber et al., 2018; Karow et al., 2018; Treutlein et al., 2016).

\section{3 - Cell division during transdifferentiation}

The acquisition of a terminal identity is traditionally linked to cell cycle exit, whereas differentiation along the lineage is associated with a succession of cell identities, normally accompanied by rounds of cell division. It is however noteworthy that differentiation can still occur if division fails (Fujita et al., 2007; Shemer and Podbilewicz, 2002). Several natural or induced direct reprogramming events occur alongside a cell division (Jopling et al., 2011): is it required in those cases and why? In this section, we will focus on transdifferentiation events in C. elegans that all include one single cell division. 


\subsection{1 - Transdifferentiation via a division - cellular paradigms}

The two amphid socket (AMso) glial cells form part of the bilateral amphid sensory organ in the head (Fig. 5A). Their anterior projection forms a pore in the cuticle through which amphid neurons contact the environment. As with PHso1 (see section 2.2), in hermaphrodite worms, the AMso cells are fully differentiated specialised cells that express a battery of glial-cell markers throughout their whole life. In males, AMso cells display the same end-of-lineage characteristics until the late L3 stage, when, coinciding with sexual maturation, they divide asymmetrically to give rise to a pair of MCM neurons. The glial projection is inherited by the anterior AMso daughters, which remain glial, and the posterior daughters express several effector neuronal genes while they cease to express glial markers. MCMs are chemosensory neurons required for a male-specific associative learning behaviour (Sammut et al., 2015).

The rectal epithelial K cell, like Y, forms part of the C. elegans rectum. It is born in the embryo and expresses effector epithelial genes until the end of the L1 larval stage, when it divides asymmetrically to produce one daughter similar to $\mathrm{K}$, and a daughter that will give rise to the GABAergic DVB neuron, involved in defecation (Fig. 5B) (Basson and Horvitz, 1996; Mclntire et al., 1993; Sulston and Horvitz, 1977; C. Riva, C. Gally, S. Jarriault, unpublished). Ultrastructural, morphological, and molecular data suggest that K-to-DVB is a true transdifferentiation (C. Riva, C. Gally, S. Jarriault, unpublished) (Fig. 5B). The rectal Y cell in males, at a similar time point to K, divides asymmetrically to give rise to two daughters, one becoming the PDA neuron and one which will generate the epithelial post-cloacal sensilla (Fig. 5C) (Sulston et al., 1980). Thus, Y-to-PDA transdifferentiation can occur with or without cell division, in males and hermaphrodites respectively (C. Riva, C. Gally, S. Jarriault, unpublished).

The G1 pore cell forms a small unicellular tube during embryogenesis that serves as the excretory pore in the head of the worm (Fig. 5D) (Sulston et al., 1983). During the L1 larval stage, this specialised epithelial cell delaminates and loses apical junctions, and divides symmetrically to generate the two motor- and interneurons RMHL/R (Thomas, 1994). Concomitantly, the G2 epithelial cell undergoes auto-wrapping to become the new excretory pore cell, replacing the G1 cell (Fig. 5E) (Parry and Sundaram, 2014; Sulston et al., 1983; Sulston and Horvitz, 1977; Sundaram and Buechner, 2016). In the early L2 stage, G2 division generates a posterior daughter that becomes the permanent pore, and an anterior daughter that further divides symmetrically to give rise to two neurons, the RMFL/R motorneurons (Stone et al., 2009; Sulston and Horvitz, 1977; Sundaram and Buechner, 2016; Thomas, 1994). Although these events occur coordinately, the identity switches are independent of one another. Both G1 and G2 are clearly specialised epithelial cells that form part of 
a functional organ and divide to produce neurons, but the mechanisms and gene expression changes that must accompany these epithelial-to-neuronal transitions remain to be characterised.

\subsection{2 - Transdifferentiation via a division - Molecular details:}

A forward genetic screen for AMso-to-MCM isolated alleles of the cyclin dependent kinase $c d k-4$ gene, which display highly specific defects of the AMso division in the male. CDK-4 is a key regulator of the G1/S transition, the first cell cycle checkpoint where cells decide to commit to division and replicate their DNA. In absence of this kinase, the AMso does not divide nor undergoes neuronal differentiation (M. Sammut, R. Poole, unpublished) (Fig. 5A). Analogous to PHso1-to-PHD, AMso-to-MCM is under the cell autonomous control of the sex determination pathway (Sammut et al., 2015). Interestingly, some of the pluripotent genes known to be required for Y-to-PDA in hermaphrodites (SEM-4, SOX-2 and EGL-27) seem dispensable for AMso-to-MCM (Molina-García et al., 2020) while most are required for K-to-DVB (C. Riva, C. Gally, S. Jarriault, unpublished). Little is known about the molecular mechanisms required for Y-toPDA in males, G1-to-RMH or G2-to-RMF. The presence of RMH neurons from G1 partially depends on ZTF-11/Myt1 (Lee et al., 2019) (Fig. 5D), reminiscent of what happens in Y-to-PDA in hermaphrodites.

\subsection{3 - Cell cycle and DNA replication}

In the first described example of transdifferentiation of the labial glands of the silk moth, as well as in Y and PHso1 where cell division does not happen, DNA replication is not required (Jarriault et al., 2008; Molina-García et al., 2020; Selman and Kafatos, 1974). However, while future work will be required to address this question, some evidence suggests that cell division cannot be uncoupled from certain transdifferentiation events. The lack of neuronal differentiation in $c d k-4$ mutants suggests that, in the AMso, passing through the cell cycle and dividing is a prerequisite for the transdifferentiation. It would be interesting to assess if triggering cell division of the hermaphrodite AMso is sufficient to generate MCM neurons, as happens with masculinised AMso cells (Sammut et al., 2015). Similarly, blocking the division of the K cell precludes the formation of a DVB neuron (C. Riva, C. Gally, S. Jarriault, unpublished). Future studies will determine if it is DNA replication, the cell partitioning, or both, that are indispensable for these processes. Therefore, it will be interesting to block DNAreplication or the cell division post-DNA replication in these cells. 


\section{Part 3 - Testing the frontiers of cellular plasticity: definitions and cellular mechanisms}

The development and lineage of C. elegans display additional events that question our definitions, including, but not reviewed here, the T cell, the IL2Q sensory neurons and the MSaaaapa embryonic blast cell (Akella et al., 2019; Luo and Horvitz, 2017; Rothman and Jarriault, 2019; Sulston et al., 1983), and may provide additional mechanistic insights into cellular plasticity. In this section we highlight selected examples that deepen the discussion.

\section{1 - The blurred borderlines of definitions}

\subsection{1 - A question of identity}

There are a number of intriguing other possible examples of transdetermination or transdifferentiation in worms. However, they cannot be assigned as such until a more detailed characterisation of initial and/or final identity is performed.

One such example are the XXX cells which are born in the embryo with a hypodermal identity. XXX cells function as part of the anterior hypodermis, but they eventually detach from it and translocate near the anterior bulb of the pharynx during embryogenesis. They then appear to lose their hypodermal identity (White, 1988) and show structural features of neurons, namely the characteristic neuronal nucleus, compact cell body, and several short axon-like processes and have been proposed to participate in neuroendocrine secretory roles in larvae and in the regulation of dauer arrest (Hu et al., 2006; Li et al., 2004; Ohkura et al., 2003; Patel et al., 2008). Thus, the XXX cell transition from an hypodermal cell to an atypical neuro-endocrine one resembles transdifferentiation without cell division. However, the degree to which they acquire these features and the possible functions of the XXX cells has not been further characterised and is necessary for a formal demonstration. Similar characterisation will be required for intriguing examples of cells with sexually dimorphic fates, such as the rectal B, U and F cells: stable end-of-lineage differentiated identity in hermaphrodite while they divide in male L1 larvae to make male-specific structures.

The seam cells are an interesting case at the crossroads of distinct concepts. On the one hand, they can be viewed as hypodermal progenitors and have been described to exhibit stem-cell like properties, like progenitor pool expansion through symmetric divisions early on, and asymmetric divisions and self-renewal (reviewed in (Joshi et al., 2010)). Moreover, certain seam cells act as neural progenitors 
(Sulston and Horvitz, 1977). On the other hand, the seam cells display a polarised epithelial morphology, express certain epithelial markers and functionally secrete cuticular components even in early larvae when still acting as dividing progenitors (Chisholm and Hsiao, 2012). Their degree of differentiation at these stages therefore remains unresolved, although in the strictest sense they are not end-of-lineage as their ultimate fate is to fuse together to form the seam syncytium. This blast cell behaviour could be indicative of a middle ground between transdifferentiation and transdetermination.

\section{1 .2 - Reversibility of cell identity}

One premise of transdifferentiation is the stability of the final identity. During the formation of the adult grinder at the L4 stage, the pm6 and pm7 pharyngeal muscle cells undergo a transformation from contractile to secretory cells (Sparacio et al., 2020). Intriguingly, this process is transient (less than 2.5 hours) as they regain ultrastructural contractile properties once the adult grinder is formed and muscle contractions resume. The reversibility of this contractile-to-secretory change challenges the premise of the stability of the second identity during transdifferentiation, and its classification as such, and raises interesting questions regarding the variation states these cells' identity might be going through.

\subsection{3 - Functional tuning}

How large should the changes in cell morphology, gene expression or function be, in order to be considered as a transdifferentiation? The answer to this question relies on how the boundaries between identities versus states are defined. There are a number of examples in worms which are likely to represent state rather than identity changes, however this classification is still far from clear. The DD motor neurons for example exhibit extensive synaptic remodelling during larval development, although DD identity and motorneuron function are preserved. The six GABA DD motoneurons are born during embryogenesis and innervate the ventral body wall muscles (BWM). At the end of the L1 stage, the DD motoneurons rewire and innervate instead the dorsal BWM (Hallam and Jin, 1998; Walthall et al., 1993; White et al., 1976) (reviewed in (Kurup and Jin, 2016)).

These changes are reminiscent of the rhodopsin switch of Drosophila melanogaster Rh5 photoreceptors (Sprecher and Desplan, 2008). During metamorphosis, the Rh5 photoreceptors repress Rh5 and activate Rh6 expression resulting in a switch in the wavelength sensitivity and a change of photoreceptor subtype. In this specific example, the question is whether the sensitivity to the same input (light) but at a different wavelength is a change in function. Another example of a generic entity constituted of a range of different cell states arising from the interactions with the environment (the 
environment of the cell, tissular or more broadly the living environment) might be offered by vertebrate T-cells - different clones specific and responsive to different antigens, but all within the Tcell identity. It does not imply that the environment itself dictates the changes - but that the different states exist so that the cells function according to their environment. Such changes in phenotype are difficult to classify although they have been previously referred to as "modulation" or "fluctuation of minor phenotypic changes" (Okada, 1991). We propose that many of these examples illustrate what could be called "functional tuning" rather than transdifferentiation.

\subsection{4 - Specific life periods: sexual maturation and starvation}

The PHC sensory neuron represents a slightly more complex example, dramatically increasing its connectivity as hub neuron that now combines sensory and interneuron features in males at sexual maturation (Serrano-Saiz et al., 2017a). Importantly, these sexually dimorphic changes are accompanied by transcriptional upregulation of glutamatergic neurotransmission and synaptic machinery, and a repurposing for male mating behaviour and vulva location. Likewise, sex-specific neurotransmitter switching coinciding with sexual maturation has been shown for several C. elegans neurons (Pereira et al., 2019, 2015b; Serrano-Saiz et al., 2017b). In fact, during sexual maturation, a number of tissues also remodel and often in a sexually dimorphic manner (reviewed in (Barr et al., 2018). In the case of the male anal depressor muscle, the function changes completely from defecation to facilitation spicule extension and sperm transfer during copulation.

All of the described plasticity events occur during normal development in well-fed animals. However, in response to an adverse environment, $C$. elegans enters into the stress-resistant dauer diapause that exhibits great plasticity in almost all tissues (reviewed in (Androwski et al., 2017)). For instance, changes are observed in the biochemical composition of the cuticle and the mitochondrial composition of muscles. The IL2 bipolar sensory neurons undergo extensive dendritic arborisation and axon remodelling upon dauer entry that is strikingly reversed upon dauer exit (Schroeder et al., 2013). Also remarkable is the neuron-type-specific changes of the combinatorial innexin code observed at the synapsis, which alters the locomotory and chemosensory behaviour of the worms (Bhattacharya et al., 2019). In many of these cases, the cohort of regulatory factors that drive these differentiated changes have been identified, broadening up the discussion on whether they represent changes in identity rather than functional tuning.

\section{2- Contribution of additional cellular mechanisms}


Two common cellular processes, not always described as cellular plasticity, could shed more light on the mechanisms of cell type switches. The first of these is epithelial-mesenchymal transition (EMT), the regulated process by which epithelial cells transition to a mesenchymal identity (reviewed in (Lamouille et al., 2014)). Epithelial and mesenchymal cells display radically different features, switching from polarised specialised epithelial cells to unpolarised motile mesenchymal cells. This could be viewed as a change of state or even a change of identity. Although EMT has not been formally identified in C. elegans, it is intriguing to note that the plasticity events described in this review, those occurring in absence of cell division in particular, involve specialised epithelial cells that delaminate and lose their epithelial characteristics (Fig. 4, 5). It is therefore interesting to speculate how similar this may be to classic EMT and if the process of delamination itself may be required for or trigger the cell identity conversion.

The second cellular process is asymmetric cell division, the process by which a mother cell gives rise to two daughters with distinct cell fates, by definition a cellular plasticity event (see section 1.3). Asymmetric cell divisions are common in C. elegans development (reviewed in (Rose and Gonczy, 2014) and (Bertrand and Hobert, 2010)); moreover, many of the transdifferentiation events we have discussed here occur in the context of an asymmetric cell division, with this specificity that the mother cell is differentiated, with end-of-lineage identity and functional integration into an organ. Asymmetric cell division, during which either two initially identical daughters receive different extracellular signals, and/or are made different by unequal distribution of specific factors (Betschinger and Knoblich, 2004), could for instance facilitate the identity swap or allow to designate one specific daughter. Whether and how the asymmetric division per se is necessary for these transdifferentiation events, is so far unresolved.

\section{Part 4 - Open questions}

To conclude, we would like to discuss four open questions concerning cellular plasticity, with a focus on natural transdifferentiation, that future investigations in C. elegans could help address.

\section{1 - What does the trajectory of a naturally reprogrammed cell like?}

Continuity of developmental trajectories and how they compare to transdifferentiation trajectories is a vexing and difficult question (see Part 1). In C. elegans, scRNA-seq data highlights both continuous and discontinuous trajectories during embryonic differentiation of specific lineages (Packer et al., 2019), but does not cover transdifferentiation events happening in the larva. Comprehensive 
approaches such as ScRNA-seq analysis of natural transdifferentiation are required to settle the controversy and would bring considerable insights in C. elegans as its development allows the study of natural events with no (or minimal) experimental alteration.

ScRNAseq are challenging to perform especially in the larvae, owing to tight developmental time windows associated with the short life cycle of the worm, low quantity of RNA content by cell, and difficulties in cell isolation, due to their cuticle, and cell purification through Fluorescence Activated Cell Sorting, due to their uniqueness and very small size. However, such data would clarify the epigenetic landscapes of natural transdifferentiation, since the number of cells at each point of the transcriptional space provides unique information on the probability of occupancy and therefore the stability on different parts of the landscape (Fig. 2D or G).

In addition, scRNA-seq of transitioning cells can bring new light on the nature (and prove the existence) of transition states. We previously suggested that the Y.1 intermediate during Y-to-PDA could resemble the neural progenitors encountered during development (Richard et al., 2011). How close are such putative TS to neural progenitors? And, if such TS can be compared to neural progenitors, how similar is the redifferentiation part of the developmental trajectory to classical neurogenesis? Expression of UNC-3 during re-differentiation into PDA suggests that similar mechanisms could be used. Finally, how similar are the trajectories of natural versus induced reprogramming (reviewed in (Rothman and Jarriault, 2019)) or regeneration? Would such a trajectory be similar, or would they be drastically different (for instance, in stability and number of the transition states or dynamics)?

\section{2 - What makes plastic cells plastic: transcriptomic heterogeneity?}

It has become clear that the loss of plasticity during development is highly connected to chromatin regulation and the implementation of 'barriers' to alternative fates and/or identity maintenance mechanisms (Ofenbauer and Tursun, 2019). Remaining plastic is therefore highly likely to involve the modification in some way of these natural barriers and this has been extensively reviewed elsewhere (Rothman and Jarriault, 2019). Other non-mutually exclusive mechanisms may also be involved and one such possibility is transcriptomic heterogeneity. Pluripotent cell populations tend to present heterogeneous profiles of gene expression with single cells exhibiting dynamic and variable profiles in time (see Part 1). This transcriptomic variability, indicating that pluripotent cells can in consequence explore the surroundings of the pluripotent attractor with ease, making them more likely to escape it, has been postulated to partly explain pluripotent cells plasticity. Is it also involved in the natural transdifferentiation of differentiated cells in C. elegans? This question could be addressed by 
exploring heterogeneity in gene expression of a cell that transdifferentiates compared to cells of the same type that show no evidence of transdifferentiation (e.g. Y cells versus non-transdifferentiating rectal cells). Such heterogeneity may come from the expression at low levels of specific gene modules, or core regulatory elements of other cell types. Together, such lowly expressed gene modules could eventually override the stable GRN configuration of the initial identity and trigger the switch. Since differentiated attractors are stable - robust to perturbations - it is unlikely that random molecular noise could override the initial stable configuration of the GRN. Therefore, even though molecular noise could be part of the transcriptomic heterogeneity of these plastic cells, it is rather the expression of specific gene modules that allows the exploration of the attractor surroundings. If transdifferentiating cells are transcriptomically more heterogeneous than the other non-transdifferentiating cells with the same identity, and more heterogenous than the final identity, this would contribute to explain the ability to transdifferentiate and the directionality of the process.

\section{3 - Why do only specific cells display plasticity?}

Only a handful of the 959 somatic cells of $C$. elegans have been described to transdifferentiate. Why are a few particular cells generated through transdifferentiation? Intriguingly, these events are similar in terms of initial specialised epithelial/glial and final neuronal identities. Why generate some neurons through transdifferentiation rather than classical neurogenesis? Is there a unifying mechanism to explain why these cells share similar initial/final identities? Here, we will speculate on several nonexclusive possible leads in answer to these questions.

Initial identity. Naturally plastic cells in C. elegans do not share a common lineage. They arise from the ABp blastomere, which gives rise to hypodermis, glia, neurons and muscles, but the lineages diverge at the ABp division and substantially prior to their formation (Sulston et al., 1983). If plasticity of certain differentiated cells cannot be explained in a lineage-dependent manner, then an alternative hypothesis could be that due to their initial function, these cells are uniquely equipped with the molecular tool-box necessary for transdifferentiation. The location of these cells, at putative entry points for pathogens and in contact with the external environment, also raise the question of whether external stimuli are required to induce transdifferentiation. Interestingly, this is a common theme in naturally occurring cell identity switches in other organisms, such as the labial gland of silk moth or pancreas islet cells. Nevertheless, current knowledge suggests some variability in the molecular mechanisms underlying the transdifferentiation events. For example, ZTF-11, SOX-2 and members of the NODE complex are required for Y-to-PDA, and probably for K-to-DVB ((Lee et al., 2019) ; C. Riva, C. Gally, S. Jarriault, unpublished) but may not all be involved in AMso-to-MCM nor PHso1-to-PHD (Molina-García et al., 2020). Transdifferentiation therefore appears to be a 
convergent property. This raises the question of whether such a convergence simply reflects opportunities (the right cells at the right place) or a selective advantage. In the latter case, what could explain this selective advantage? One obvious hypothesis could be that transdifferentiation allows two sequential functions to be performed by one cell, which could be particularly beneficial in organisms with limited numbers of cells.

Final identity. Is transdifferentiation toward mostly neurons an indicator of such a selective pressure, i.e. generating more cells of that cell type has the most beneficial impact on the animal's fitness? Are reprogramming barriers such that generating neurons from these initial identities is the easiest path? Or are the former specialised epithelial/glial identities of neurons produced by transdifferentiation beneficial for the neurons' performance? Or perhaps one benefit of generating cells through transdifferentiation is to generate some specific neurons at a specific point in space and time. In line with this timing hypothesis, the MCM neurons connect to pre-exisiting neuronal circuits and modify male behaviour late, during sexual maturation for optimal mating behaviour (Sammut et al., 2015). At earlier stages before they are mature, males do not need to prioritise these behaviours. DVB, involved in ensuring optimal defecation, also arises at a time the larvae start feeding. Another possibility is that very specific structures must already be in place prior to their generation, for optimal functioning/wiring. This could be because they need structural support to function correctly, and the initial identity is important for the supporting structure to be made. A further hypothesis would thus be that the function of newborn neurons is related to the organ function they were a part of, or close to, in their former life.

\section{4 - Why do some transdifferentiations occur with a cell division and others do not?}

Natural transdifferentiation in the worm can happen with or without cellular division, but why is that? In the previous section we discussed the benefit of having one cell successively performing two functions thanks to transdifferentiation. Conversely, such events implicate the loss of the cell of origin, which might compromise the structure to which it once belonged. In Y-to-PDA, P12.pa replaces the $\mathrm{Y}$ cell after its retraction from the rectum, thus maintaining the tubular structure of the rectum. By contrast, in the amphid sensillum, the AMso is required to form the socket and self-renews during the division that occurs with MCM transdifferentiation. When such structural or functional requirements are maintained after transdifferentiation and no 'substitute cell' are available, transdifferentiation would require cell division to be viable.

In addition to generating one additional cell, several hypotheses can be made with regard to the potential role of cell division in transdifferentiation: (1) the division can allow for the asymmetric 
segregation of fate determinants, or place one daughter cell in an inductive environment (2) Cell division may be a quicker way to achieve transdifferentiation, for instance because it is a powerful way of remodelling the epigenetic landscape, giving new transcriptional opportunities for a change in cell identity. Some newborn neurons may be required more urgently than others, and thus the organism would benefit from quicker transdifferentiation modes. Interestingly, K-to-DVB is a quicker transdifferentiation than Y-to-PDA (C. Gally, C. Riva, S. Jarriault, unpublished) and DVB has been implicated in defecation, an early vital function.

Histone modifications seem necessary for robust transdifferentiation (Zuryn et al., 2014), indicating the need to clarify how transdifferentiation without cell division achieves the establishment of a new chromatin landscape. Interestingly, the MTA homolog egl-27 is required for Y-to-PDA initiation (no cell division) but not for AMso-to-MCM (with cell division) (Kagias et al., 2012; Molina-García et al., 2020). This may indicate that additional chromatin factors remodel the chromatin during the initiation step, acting as keys that unlock the chromatin landscape in the cases without divisions.

\section{Concluding remarks}

Cell identity and plasticity is a fascinating topic that has attracted renewed interest in the past decades. C. elegans is an interesting model to investigate issues pertaining to cellular plasticity as its set of relatively small and fixed number of well-characterised cells illustrates a plurality of situations. Although, based on current knowledge, most cells seem to fit the traditional view of an unidirectional irreversible differentiation path toward fixed differentiated cells, some incontestably show great plasticity and can transdifferentiate, and yet others sit at the edge of plasticity questioning the boundaries of cell plasticity and the definition of cell identity. As the sensitivity of comprehensive technologies will continue to improve and new data be generated, we expect this debate to deepen and refine these concepts. The recent studies of these transdifferentiation events highlight a collection of processes that, for example, might or might not require cell division, or intermediate distinct identities. It is our conviction that better understanding plasticity, and more generally cell identity, requires both experimental investigation as well as modelling and conceptual work. We highlighted how adopting particular definitions or frameworks, such as the now widespread Waddington landscape, can constrain the interpretation of phenomenon. We have discussed alternative views and opened questions for the future, such as why only a few cells, all neurons, are generated by transdifferentiation, and why they do not arise from classical neurogenesis. 


\section{Acknowledgements:}

We apologise to all those whose work on various aspects of plasticity we could not cover for space constraints. We are grateful to Christelle Gally, Luisa Cochella, and members of the Poole and Jarriault labs for insightful comments on the manuscript and thank Sheila Poole for edits. This work was supported by a Wellcome Senior Research Fellowship (207483/Z/17/Z) awarded to RJP; an ANR grant STEM ANR-19-CE27-0027-01 and a James S. McDonnell Foundation grant "Transforming Discovery: Historians, Philosophers, and Life Scientists Exploring Regeneration” awarded to LL; and an ERC CoG (European Research Council Consolidator Grant) PlastiCell grant \#648960 awarded to

SJ. SJ is a CNRS research director.

\section{Literature}

1. Abranches, E., Guedes, A.M.V., Moravec, M., Maamar, H., Svoboda, P., Raj, A., Henrique, D., 2014. Stochastic NANOG fluctuations allow mouse embryonic stem cells to explore pluripotency. Dev. 141, 2770-2779. https://doi.org/10.1242/dev.108910

2. Akella, J.S., Silva, M., Morsci, N.S., Nguyen, K.C., Rice, W.J., Hall, D.H., Barr, M.M., 2019. Cell type-specific structural plasticity of the ciliary transition zone in C. elegans. Biol. cell 111, 95-107. https://doi.org/10.1111/boc.201800042

3. Albert Hubbard, E.J., Schedl, T., 2019. Biology of the caenorhabditis elegans germline stem cell system. Genetics 213, 1145-1188. https://doi.org/10.1534/genetics.119.300238

4. Allen, M., 2015. Compelled by the Diagram: Thinking through C. H. Waddington's Epigenetic Landscape. Contemp. Hist. Presence Vis. Cult. 4, 119-142.

https://doi.org/10.5195/contemp.2015.143

5. Altun, Z.., Hall, D.., 2010. Nervous system, neuronal support cells. WormAtlas. https://doi.org/doi:10.3908/wormatlas.1.19

6. Androwski, R.J., Flatt, K.M., Schroeder, N.E., 2017. Phenotypic plasticity and remodeling in the stress-induced Caenorhabditis elegans dauer. Wiley Interdiscip. Rev. Dev. Biol. 6. https://doi.org/10.1002/wdev.278

7. Araya, C.L., Kawli, T., Kundaje, A., Jiang, L., Wu, B., Vafeados, D., Terrell, R., Weissdepp, P., Gevirtzman, L., Mace, D., Niu, W., Boyle, A.P., Xie, D., Ma, L., Murray, J.I., Reinke, V., Waterston, R.H., Snyder, M., 2014. Regulatory analysis of the C. elegans genome with spatiotemporal resolution. Nature 512, 400-405. https://doi.org/10.1038/nature13497 
8. Arendt, D., 2008. The evolution of cell types in animals: emerging principles from molecular studies. Nat. Rev. Genet. 9, 868-882. https://doi.org/10.1038/nrg2416

9. Arendt, D., Musser, J.M., Baker, C.V.H., Bergman, A., Cepko, C., Erwin, D.H., Pavlicev, M., Schlosser, G., Widder, S., Laubichler, M.D., Wagner, G.P., 2016. The origin and evolution of cell types. Nat. Rev. Genet. 17, 744-757. https://doi.org/10.1038/nrg.2016.127

10. Barr, M.M., García, L.R., Portman, D.S., 2018. Sexual Dimorphism and Sex Differences in Caenorhabditis elegans Neuronal Development and Behavior. Genetics 208, 909-935. https://doi.org/10.1534/genetics.117.300294

11. Basson, M., Horvitz, H.R., 1996. The Caenorhabditis elegans gene sem-4 controls neuronal and mesodermal cell development and encodes a zinc finger protein. Genes Dev. 10, 19531965. https://doi.org/10.1101/gad.10.15.1953

12. Bertrand, V., Hobert, O., 2010. Lineage programming: navigating through transient regulatory states via binary decisions. Curr. Opin. Genet. Dev. 20, 362-368. https://doi.org/10.1016/j.gde.2010.04.010

13. Betschinger, J., Knoblich, J.A., 2004. Dare to be different: asymmetric cell division in Drosophila, C. elegans and vertebrates. Curr. Biol. 14, R674-85. https://doi.org/10.1016/j.cub.2004.08.017

14. Bhattacharya, A., Aghayeva, U., Berghoff, E.G., Hobert, O., 2019. Plasticity of the Electrical Connectome of C. elegans. Cell 176, 1174-1189.e16.

https://doi.org/10.1016/j.cell.2018.12.024

15. Bjornson, C.R.R., Rietze, R.L., Reynolds, B.A., Magli, M.C., Vescovi, A.L., 1999. Turning brain into blood: A hematopoietic fate adopted by adult neural stem cells in vivo. Science 283, 534-537. https://doi.org/10.1126/science.283.5401.534

16. Blau, H.M., Pavlath, G.K., Hardeman, E.C., Chiu, C.P., Silberstein, L., Webster, S.G., Miller, S.C., Webster, C., 1985. Plasticity of the differentiated state. Science (80-. ). 230, 758-766. https://doi.org/10.1126/science.2414846

17. Brackston, R.D., Lakatos, E., Stumpf, M.P.H., 2018. Characteristics During Cell Differentiation. PLoS Comput. Biol. 14, e1006405.

18. Brenner, S., 1974. The Genetics of Caenorhabditis elegans. Genetics 71-94.

19. Britten, R.J., Davidson, E.H., 1969. Gene Regulation for Higher Cells: A Theory. Science 165, 349 LP - 357. https://doi.org/10.1126/science.165.3891.349

20. Brockes, J.P., Kumar, A., 2002. Plasticity and reprogramming of differentiated cells in amphibian regeneration. Nat. Rev. Mol. Cell Biol. 3, 566-574. https://doi.org/10.1038/nrm881

21. Brumbaugh, J., Stefano, B. Di, Hochedlinger, K., 2019. Reprogramming: Identifying the mechanisms that safeguard cell identity. Dev. 146, 1-17. https://doi.org/10.1242/dev.182170

22. Cao, J., Packer, J.S., Ramani, V., Cusanovich, D.A., Huynh, C., Daza, R., Qiu, X., Lee, C., Furlan, S.N., Steemers, F.J., Adey, A., Waterston, R.H., Trapnell, C., Shendure, J., 2017. 
Comprehensive single-cell transcriptional profiling of a multicellular organism. Science 357, 661-667. https://doi.org/10.1126/science.aam8940

23. Chalfie, M., Tu, Y., Euskirchen, G., Ward, W.W., Prasher, D.C., 1994. Green fluorescent protein as a marker for gene expression. Science 263, 802-805.

https://doi.org/10.1126/science.8303295

24. Chambers, I., Silva, J., Colby, D., Nichols, J., Nijmeijer, B., Robertson, M., Vrana, J., Jones, K., Grotewold, L., Smith, A., 2007. Nanog safeguards pluripotency and mediates germline development. Nature 450, 1230-1234. https://doi.org/10.1038/nature06403

25. Chisholm, A.D., Hsiao, T.I., 2012. The Caenorhabditis elegans epidermis as a model skin. I: development, patterning, and growth. WIREs Dev. Biol. 1, 861-878.

https://doi.org/https://doi.org/10.1002/wdev.79

26. Coraggio, F., Püschel, R., Marti, A., Meister, P., 2019. Polycomb and Notch signaling regulate cell proliferation potential during Caenorhabditis elegans life cycle. Life Sci. Alliance 2, 1-12. https://doi.org/10.26508/1sa.201800170

27. Corson, F., Siggia, E.D., 2012. Geometry, epistasis, and developmental patterning. Proc. Natl. Acad. Sci. U. S. A. 109, 5568-5575. https://doi.org/10.1073/pnas.1201505109

28. Crane, E., Bian, Q., McCord, R.P., Lajoie, B.R., Wheeler, B.S., Ralston, E.J., Uzawa, S., Dekker, J., Meyer, B.J., 2015. Condensin-driven remodelling of X chromosome topology during dosage compensation. Nature 523, 240-244. https://doi.org/10.1038/nature14450

29. Di Tullio, A., Vu Manh, T.P., Schubert, A., Månsson, R., Graf, T., 2011. CCAAT/enhancer binding protein $\alpha(\mathrm{C} / \mathrm{EBP} \alpha)$-induced transdifferentiation of pre-B cells into macrophages involves no overt retrodifferentiation. Proc. Natl. Acad. Sci. U. S. A. 108, 17016-17021. https://doi.org/10.1073/pnas.1112169108

30. Ding, H., Xu, X., Qin, X., Yang, C., Feng, Q., 2016. Resveratrol promotes differentiation of mouse embryonic stem cells to cardiomyocytes. Cardiovasc. Ther. 34, 283-289.

https://doi.org/https://doi.org/10.1111/1755-5922.12200

31. Djabrayan, N.J.-V., Dudley, N.R., Sommermann, E.M., Rothman, J.H., 2012. Essential role for Notch signaling in restricting developmental plasticity. Genes Dev. 26, 2386-2391. https://doi.org/10.1101/gad.199588.112

32. Doan, C.A., 1939. On the Origin and Developmental Potentialities of Blood Cells. Bull. N. Y. Acad. Med. 15, 668-697.

33. Doitsidou, M., Poole, R.J., Sarin, S., Bigelow, H., Hobert, O., 2010. C. elegans mutant identification with a one-step whole-genome-sequencing and SNP mapping strategy. PLoS One 5, e15435. https://doi.org/10.1371/journal.pone.0015435

34. Dunn, J., Qiu, H., Kim, S., Jjingo, D., Hoffman, R., Kim, C.W., Jang, I., Son, D.J., Kim, D., Pan, C., Fan, Y., Jordan, I.K., Jo, H., 2014. Flow-dependent epigenetic DNA methylation regulates endothelial gene expression and atherosclerosis. J. Clin. Invest. 124, 3187-3199. https://doi.org/10.1172/JCI74792 
35. Durham, T.J., Daza, R.M., Gevirtzman, L., Cusanovich, D.A., Noble, W.S., Shendure, J., Waterston, R.H., 2020. Comprehensive characterization of tissue-specific chromatin accessibility in L2 Caenorhabditis elegans nematodes. bioRxiv 2020.09.15.299123. https://doi.org/10.1101/2020.09.15.299123

36. Efe, J.A., Hilcove, S., Kim, J., Zhou, H., Ouyang, K., Wang, G., Chen, J., Ding, S., 2011. Conversion of mouse fibroblasts into cardiomyocytes using a direct reprogramming strategy. Nat. Cell Biol. 13, 215-222. https://doi.org/10.1038/ncb2164

37. Eguchi, G., Kodama, R., 1993. Transdifferentiation. Curr. Opin. Cell Biol. 2, 1023-1028. https://doi.org/10.1016/B978-012436643-5/50103-6

38. Eguchi, G., Abe, S.I., Watanabe, K., 1974. Differentiation of lens-like structures from newt iris epithelial cells in vitro. Proc. Natl. Acad. Sci. U. S. A. 71, 5052-5056. https://doi.org/10.1073/pnas.71.12.5052

39. Eguizabal, C., Aran, B., Chuva de Sousa Lopes, S.M., Geens, M., Heindryckx, B., Panula, S., Popovic, M., Vassena, R., Veiga, A., 2019. Two decades of embryonic stem cells: a historical overview. Hum. Reprod. Open 2019. https://doi.org/10.1093/hropen/hoy024

40. Fejer, G., Wegner, M.D., Györy, I., Cohen, I., Engelhard, P., Voronov, E., Manke, T., Ruzsics, Z., Dölken, L., Prazeres da Costa, O., Branzk, N., Huber, M., Prasse, A., Schneider, R., Apte, R.N., Galanos, C., Freudenberg, M.A., 2013. Nontransformed, GM-CSF-dependent macrophage lines are a unique model to study tissue macrophage functions. Proc. Natl. Acad. Sci. U. S. A. 110, E2191-8. https://doi.org/10.1073/pnas.1302877110

41. Ferrari, G., Cusella-De Angelis, G., Coletta, M., Paolucci, E., Stornaiuolo, A., Cossu, G., Mavilio, F., 1998. Muscle regeneration by bone marrow-derived myogenic progenitors. Science (80-. ). 279, 1528-1530. https://doi.org/10.1126/science.279.5356.1528

42. Ferrell, J.E., 2012. Bistability, bifurcations, and Waddington's epigenetic landscape. Curr. Biol. 22, R458-R466. https://doi.org/10.1016/j.cub.2012.03.045

43. Fujita, M., Takeshita, H., Sawa, H., 2007. Cyclin E and CDK2 Repress the Terminal Differentiation of Quiescent Cells after Asymmetric Division in C. elegans. PLoS One 2, e407.

44. Fukushige, T., Krause, M., 2005. The myogenic potency of HLH-1 reveals wide-spread developmental plasticity in early C. elegans embryos. Development 132, 1795-1805. https://doi.org/10.1242/dev.01774

45. Gao, A.W., Sterken, M.G., Uit de Bos, J., van Creij, J., Kamble, R., Snoek, B.L., Kammenga, J.E., Houtkooper, R.H., 2018. Natural genetic variation in C. elegans identified genomic loci controlling metabolite levels. Genome Res. 28, 1296-1308. https://doi.org/10.1101/gr.232322.117

46. Gehart, H., Clevers, H., 2019. Tales from the crypt: new insights into intestinal stem cells. Nat. Rev. Gastroenterol. Hepatol. 16, 19-34. https://doi.org/10.1038/s41575-018-0081-y

47. Gerber, T., Murawala, P., Knapp, D., Masselink, W., Schuez, M., Hermann, S., Gac-Santel, M., Nowoshilow, S., Kageyama, J., Khattak, S., Currie, J.D., Camp, J.G., Tanaka, E.M., 
Treutlein, B., 2018. Single-cell analysis uncovers convergence of cell identities during axolotl limb regeneration. Science (80-. ). 362. https://doi.org/10.1126/science.aaq0681

48. Gilleard, J.S., McGhee, J.D., 2001. Activation of hypodermal differentiation in the Caenorhabditis elegans embryo by GATA transcription factors ELT-1 and ELT-3. Mol. Cell. Biol. 21, 2533-2544. https://doi.org/10.1128/mcb.21.7.2533-2544.2001

49. Gómez-Saldivar, G., Osuna-Luque, J., Semple, J.I., Glauser, D.A., Jarriault, S., Meister, P., 2020. Tissue-Specific Transcription Footprinting Using RNA PoI DamID (RAPID) in Caenorhabditis elegans. Genetics 216, 931-945. https://doi.org/10.1534/genetics. 120.303774

50. González-Aguilera, C., Palladino, F., Askjaer, P., 2014. C. elegans epigenetic regulation in development and aging. Brief. Funct. Genomics 13, 223-234.

https://doi.org/10.1093/bfgp/elt048

51. Guo, Z., Zhang, L., Wu, Z., Chen, Y., Wang, F., Chen, G., 2014. In vivo direct reprogramming of reactive glial cells into functional neurons after brain injury and in an Alzheimer's disease model. Cell Stem Cell 14, 188-202. https://doi.org/10.1016/j.stem.2013.12.001

52. Gurdon, J.B., 1967. On the origin and persistence of a cytoplasmic state inducing nuclear DNA synthesis in frogs' eggs. Proc. Natl. Acad. Sci. U. S. A. 58, 545-552. https://doi.org/10.1073/pnas.58.2.545

53. Gurdon, J.B., 1962. The developmental capacity of nuclei taken from intestinal epithelium cells of feeding tadpoles. J. Embryol. Exp. Morphol. 10, 622-640.

54. Hallam, S.J., Jin, Y., 1998. lin-14 regulates the timing of synaptic remodelling in Caenorhabditis elegans. Nature 395, 78-82. https://doi.org/10.1038/25757

55. Hansson, J., Rafiee, M.R., Reiland, S., Polo, J.M., Gehring, J., Okawa, S., Huber, W., Hochedlinger, K., Krijgsveld, J., 2012. Highly Coordinated Proteome Dynamics during Reprogramming of Somatic Cells to Pluripotency. Cell Rep. 2, 1579-1592. https://doi.org/10.1016/j.celrep.2012.10.014

56. Hastings, J., Mains, A., Virk, B., Rodriguez, N., Murdoch, S., Pearce, J., Bergmann, S., Le Novère, N., Casanueva, O., 2019. Multi-omics and genome-scale modeling reveal a metabolic shift during C. elegans aging. Front. Mol. Biosci. 6. https://doi.org/10.3389/fmolb.2019.00002

57. Heinrich, C., Blum, R., Gascón, S., Masserdotti, G., Tripathi, P., Sánchez, R., Tiedt, S., Schroeder, T., Götz, M., Berninger, B., 2010. Directing astroglia from the cerebral cortex into subtype specific functional neurons. PLoS Biol. 8, e1000373. https://doi.org/10.1371/journal.pbio.1000373

58. Henry, J.J., Tsonis, P.A., 2010. Molecular and cellular aspects of amphibian lens regeneration. Prog. Retin. Eye Res. 29, 543-555. https://doi.org/10.1016/j.preteyeres.2010.07.002

59. Hobert, O., 2016. A map of terminal regulators of neuronal identity in Caenorhabditis elegans. Wiley Interdiscip. Rev. Dev. Biol. 5, 474-498. https://doi.org/10.1002/wdev.233 
60. Hobert, O., 2008. Regulatory logic of neuronal diversity: terminal selector genes and selector motifs. Proc. Natl. Acad. Sci. U. S. A. 105, 20067-20071. https://doi.org/10.1073/pnas.0806070105

61. Holmberg, J., Perlmann, T., 2012. Maintaining differentiated cellular identity. Nat. Rev. Genet. 13, 429-439. https://doi.org/10.1038/nrg3209

62. Horner, M.A., Quintin, S., Domeier, M.E., Kimble, J., Labouesse, M., Mango, S.E., 1998. pha4, an HNF-3 homolog, specifies pharyngeal organ identity in Caenorhabditis elegans. Genes Dev. 12, 1947-1952. https://doi.org/10.1101/gad.12.13.1947

63. Horvitz, H.R., Sulston, J.E., 1980. Isolation and genetic characterization of cell-lineage mutants of the nematode Caenorhabditis elegans. Genetics 96, 435-454.

64. Hu, P.J., Xu, J., Ruvkun, G., 2006. Two membrane-associated tyrosine phosphatase homologs potentiate C. elegans AKT-1/PKB signaling. PLoS Genet. 2, e99.

https://doi.org/10.1371/journal.pgen.0020099

65. Huang, B., Ning, S., Zhuang, L., Jiang, C., Cui, Y., Fan, G., Qin, L., Liu, J., 2015. Ethanol Inactivated Mouse Embryonic Fibroblasts Maintain the Self-Renew and Proliferation of Human Embryonic Stem Cells. PLoS One 10, e0130332. https://doi.org/10.1371/journal.pone.0130332

66. Huang, S., 2012. The molecular and mathematical basis of Waddington's epigenetic landscape: A framework for post-Darwinian biology? BioEssays 34, 149-157. https://doi.org/10.1002/bies.201100031

67. Huang, S., 2010. Cell lineage determination in state space: A systems view brings flexibility to dogmatic canonical rules. PLoS Biol. 8, 8-11. https://doi.org/10.1371/journal.pbio.1000380

68. Huang, S., Eichler, G., Bar-Yam, Y., Ingber, D.E., 2005. Cell fates as high-dimensional attractor states of a complex gene regulatory network. Phys. Rev. Lett. 94, 128701. https://doi.org/10.1103/PhysRevLett.94.128701

69. Hyman, L.H., 1960. Neue Beitrage zur Entwicklungsmechanik der Nematoden. Otto zur Strassen . Q. Rev. Biol. 35, 240. https://doi.org/10.1086/403138

70. Ieda, M., Fu, J.-D., Delgado-Olguin, P., Vedantham, V., Hayashi, Y., Bruneau, B.G., Srivastava, D., 2010. Direct reprogramming of fibroblasts into functional cardiomyocytes by defined factors. Cell 142, 375-386. https://doi.org/10.1016/j.cell.2010.07.002

71. Jänes, J., Dong, Y., Schoof, M., Serizay, J., Appert, A., Cerrato, C., Woodbury, C., Chen, R., Gemma, C., Huang, N., Kissiov, D., Stempor, P., Steward, A., Zeiser, E., Sauer, S., Ahringer, J., 2018. Chromatin accessibility dynamics across c. Elegans development and ageing. Elife 7, 1-24. https://doi.org/10.7554/eLife.37344

72. Jarriault, S., Schwab, Y., Greenwald, I., 2008. A Caenorhabditis elegans model for epithelialneuronal transdifferentiation. Proc. Natl. Acad. Sci. U. S. A. 105, 3790-3795. https://doi.org/10.1073/pnas.0712159105 
73. Jin, Y., Hoskins, R., Horvitz, H.R., 1994. Control of type-D GABAergic neuron differentiation by C. elegans UNC-30 homeodomain protein. Nature 372, 780-783.

74. Jopling, C., Boue, S., Belmonte, J.C.I., 2011. Dedifferentiation, transdifferentiation and reprogramming: three routes to regeneration. Nat. Rev. Mol. Cell Biol. 12, 79-89. https://doi.org/10.1038/nrm3043

75. Joshi, P.M., Riddle, M.R., Djabrayan, N.J. V, Rothman, J.H., 2010. Caenorhabditis elegans as a model for stem cell biology. Dev. Dyn. 239, 1539-1554. https://doi.org/10.1002/dvdy.22296

76. Junkersdorf, B., Schierenberg, E., 1992. Embryogenesis in C. elegans after elimination of individual blastomeres or induced alteration of the cell division order. Roux's Arch. Dev. Biol. 202, 17-22. https://doi.org/10.1007/BF00364593

77. Kagias, K., Ahier, A., Fischer, N., Jarriault, S., 2012. Members of the NODE (Nanog and Oct4-associated deacetylase) complex and SOX-2 promote the initiation of a natural cellular reprogramming event in vivo. Proc. Natl. Acad. Sci. U. S. A. 109, 6596-6601. https://doi.org/10.1073/pnas.1117031109

78. Kalmar, T., Lim, C., Hayward, P., Muñoz-Descalzo, S., Nichols, J., Garcia-Ojalvo, J., Martinez Arias, A., 2009. Regulated fluctuations in nanog expression mediate cell fate decisions in embryonic stem cells. PLoS Biol. 7, e1000149. https://doi.org/10.1371/journal.pbio.1000149

79. Kapoor, N., Liang, W., Marbán, E., Cho, H.C., 2013. Direct conversion of quiescent cardiomyocytes to pacemaker cells by expression of Tbx18. Nat. Biotechnol. 31, 54-62. https://doi.org/10.1038/nbt.2465

80. Karow, M., Gray Camp, J., Falk, S., Gerber, T., Pataskar, A., Gac-Santel, M., Kageyama, J., Brazovskaja, A., Garding, A., Fan, W., Riedemann, T., Casamassa, A., Smiyakin, A., Schichor, C., Götz, M., Tiwari, V.K., Treutlein, B., Berninger, B., 2018. Direct pericyte-toneuron reprogramming via unfolding of a neural stem cell-like program. Nat. Neurosci. 21, 932-940. https://doi.org/10.1038/s41593-018-0168-3

81. Karow, M., Sánchez, R., Schichor, C., Masserdotti, G., Ortega, F., Heinrich, C., Gascón, S., Khan, M.A., Lie, D.C., Dellavalle, A., Cossu, G., Goldbrunner, R., Götz, M., Berninger, B., 2012. Reprogramming of pericyte-derived cells of the adult human brain into induced neuronal cells. Cell Stem Cell 11, 471-476. https://doi.org/10.1016/j.stem.2012.07.007

82. Kauffman, S.A., 1992. The Origins of Order: Self-Organization and Selection in Evolution 61100. https://doi.org/10.1142/9789814415743_0003

83. Kauffman, S.A., 1969. Metabolic stability and epigenesis in randomly constructed genetic nets. J. Theor. Biol. 22, 437-467. https://doi.org/https://doi.org/10.1016/0022-5193(69)900150

84. Kaur, S., Mélénec, P., Murgan, S., Bordet, G., 2020. Wnt ligands regulate the asymmetric divisions of neuronal progenitors in C . elegans embryos. Development.

https://doi.org/10.1242/dev.183186 
85. Kelly, W.G., 2014. Transgenerational epigenetics in the germline cycle of Caenorhabditis elegans. Epigenetics Chromatin 7, 6. https://doi.org/10.1186/1756-8935-7-6

86. Kemphues, K.J., Kusch, M., Wolf, N., 1988. Maternal-effect lethal mutations on linkage group II of Caenorhabditis elegans. Genetics 120, 977 LP - 986.

87. King, T.J., Briggs, R., 1955. Changes in the nuclei of differentiating gastrula cells, as demonstrated by nuclear transplantation. Proc. Natl. Acad. Sci. U. S. A. 41, 321-325. https://doi.org/10.1073/pnas.41.5.321

88. Kodama, R., Eguchi, G., 1995. From lens regeneration in the newt to in-vitro transdifferentiation of vertebrate pigmented epithelial cells. Semin. Cell Biol. 6, 143-149. https://doi.org/10.1006/scel.1995.0020

89. Koizumi, O., Bode, H.R., 1991. Plasticity in the nervous system of adult hydra. III. Conversion of neurons to expression of a vasopressin-like immunoreactivity depends on axial location. J. Neurosci. 11, 2011-2020. https://doi.org/10.1523/JNEUROSCI.11-07-02011.1991

90. Koizumi, O., Bode, H.R., 1986. Plasticity in the nervous system of adult hydra. I. The position-dependent expression of FMRFamide-like immunoreactivity. Dev. Biol. 116, 407421. https://doi.org/10.1016/0012-1606(86)90142-9

91. Kraft, A., Rubin, B.P., 2016. Changing cells: An analysis of the concept of plasticity in the context of cellular differentiation. Biosocieties 11, 497-525. https://doi.org/10.1057/s41292016-0027-y

92. Kroehne, V., Freudenreich, D., Hans, S., Kaslin, J., Brand, M., 2011. Regeneration of the adult zebrafish brain from neurogenic radial glia-type progenitors. Development 138, 4831-4841. https://doi.org/10.1242/dev.072587

93. Kurian, L., Sancho-Martinez, I., Nivet, E., Aguirre, A., Moon, K., Pendaries, C., VolleChallier, C., Bono, F., Herbert, J., Pulecio, J., Xia, Y., Li, M., Montserrat, N., Ruiz, S., Dubova, I., Rodriguez, C., Denli, A.M., Boscolo, F.S., Thiagarajan, R.D., Gage, F.H., Loring, J.F., Laurent, L.C., Izpisua Belmonte, J.C., 2013. Conversion of human fibroblasts to angioblast-like progenitor cells. Nat. Methods 10,77-83. https://doi.org/10.1038/nmeth.2255

94. Kurup, N., Jin, Y., 2016. Neural circuit rewiring: insights from DD synapse remodeling. Worm 5, e1129486. https://doi.org/10.1080/21624054.2015.1129486

95. Kutscher, L.M., Shaham, S., 2014. Forward and reverse mutagenesis in C. elegans. WormBook 36, 1-26. https://doi.org/10.1895/wormbook.1.167.1

96. Lamouille, S., Xu, J., Derynck, R., 2014. Molecular mechanisms of epithelial-mesenchymal transition. Nat. Rev. Mol. Cell Biol. 15, 178-196. https://doi.org/10.1038/nrm3758

97. Laranjeira, C., Sandgren, K., Kessaris, N., Richardson, W., Potocnik, A., Vanden Berghe, P., Pachnis, V., 2011. Glial cells in the mouse enteric nervous system can undergo neurogenesis in response to injury. J. Clin. Invest. 121, 3412-3424. https://doi.org/10.1172/JCI58200 
98. Laufer, J.S., Bazzicalupo, P., Wood, W.B., 1980. Segregation of developmental potential in early embryos of caenorhabditis elegans. Cell 19, 569-577. https://doi.org/10.1016/S00928674(80)80033-X

99. Laurenti, E., Göttgens, B., 2018. From haematopoietic stem cells to complex differentiation landscapes. Nature 553, 418-426. https://doi.org/10.1038/nature25022

100. Lee, J., Taylor, C.A., Barnes, K.M., Shen, A., Stewart, E. V., Chen, A., Xiang, Y.K., Bao, Z., Shen, K., 2019. A Myt1 family transcription factor defines neuronal fate by repressing nonneuronal genes. Elife 8, 1-31. https://doi.org/10.7554/eLife.46703

101. Lesa, G.M., 2006. Isolation of Caenorhabditis elegans gene knockouts by PCR screening of chemically mutagenized libraries. Nat. Protoc. 1, 2231-2240.

https://doi.org/10.1038/nprot.2006.345

102. Li, C., Wang, J., 2013. Quantifying waddington landscapes and paths of non-adiabatic cell fate decisions for differentiation, reprogramming and transdifferentiation. J. R. Soc. Interface 10. https://doi.org/10.1098/rsif.2013.0787

103. Li, J., Brown, G., Ailion, M., Lee, S., Thomas, J.H., 2004. NCR-1 and NCR-2, the C. elegans homologs of the human Niemann-Pick type $\mathrm{C} 1$ disease protein, function upstream of DAF-9 in the dauer formation pathways. Development 131, 5741-5752.

https://doi.org/10.1242/dev.01408

104. Li, W.-C., Yu, W.-Y., Quinlan, J.M., Burke, Z.D., Tosh, D., 2005. The molecular basis of transdifferentiation. J. Cell. Mol. Med. 9, 569-582. https://doi.org/10.1111/j.15824934.2005.tb00489.x

105. Lippincott-Schwartz, J., Patterson, G.H., 2003. Development and use of fluorescent protein markers in living cells. Science 300, 87-91. https://doi.org/10.1126/science.1082520

106. Logan, C.Y., Desai, T.J., 2015. Keeping it together: Pulmonary alveoli are maintained by a hierarchy of cellular programs. Bioessays 37, 1028-1037.

https://doi.org/10.1002/bies.201500031

107. Luo, S., Horvitz, H.R., 2017. The CDK8 Complex and Proneural Proteins Together Drive Neurogenesis from a Mesodermal Lineage. Curr. Biol. 27, 661-672.

https://doi.org/https://doi.org/10.1016/j.cub.2017.01.056

108. MacArthur, B.D., Lemischka, I.R., 2013. Statistical mechanics of pluripotency. Cell 154, 484489. https://doi.org/10.1016/j.cell.2013.07.024

109. MacArthur, B.D., Sevilla, A., Lenz, M., Müller, F.-J., Schuldt, B.M., Schuppert, A.A., Ridden, S.J., Stumpf, P.S., Fidalgo, M., Ma'ayan, A., Wang, J., Lemischka, I.R., 2012. Nanogdependent feedback loops regulate murine embryonic stem cell heterogeneity. Nat. Cell Biol. 14, 1139-1147. https://doi.org/10.1038/ncb2603

110. MacLean, A.L., Hong, T., Nie, Q., 2018. Exploring intermediate cell states through the lens of single cells. Curr. Opin. Syst. Biol. 9, 32-41. https://doi.org/10.1016/j.coisb.2018.02.009 
111. Marr, C., Zhou, J.X., Huang, S., 2016. Single-cell gene expression profiling and cell state dynamics: Collecting data, correlating data points and connecting the dots. Curr. Opin. Biotechnol. 39, 207-214. https://doi.org/10.1016/j.copbio.2016.04.015

112. Maves, L., Schubiger, G., 1995. Wingless induces transdetermination in developing Drosophila imaginal discs. Development 121, 1263-1272.

113. Maza, I., Caspi, I., Zviran, A., Chomsky, E., Rais, Y., Viukov, S., Geula, S., Buenrostro, J.D., Weinberger, L., Krupalnik, V., Hanna, S., Zerbib, M., Dutton, J.R., Greenleaf, W.J., Massarwa, R., Novershtern, N., Hanna, J.H., 2015. Transient acquisition of pluripotency during somatic cell transdifferentiation with iPSC reprogramming factors. Nat. Biotechnol. 33, 769-774. https://doi.org/10.1038/nbt.3270

114. McCallum, S., Obata, Y., Fourli, E., Boeing, S., Peddie, C.J., Xu, Q., Horswell, S., Kelsh, R.N., Collinson, L., Wilkinson, D., Pin, C., Pachnis, V., Heanue, T.A., 2020. Enteric glia as a source of neural progenitors in adult zebrafish. Elife 9. https://doi.org/10.7554/eLife.56086

115. Mclntire, S.L., Jorgensen, E., Kaplan, J., Horvitz, H.R., 1993. The GABAergic nervous system of Caenorhabditis elegans. Nature 364, 337-341. https://doi.org/10.1038/364337a0

116. Means, A.L., Meszoely, I.M., Suzuki, K., Miyamoto, Y., Rustgi, A.K., Coffey, R.J.J., Wright, C.V.E., Stoffers, D.A., Leach, S.D., 2005. Pancreatic epithelial plasticity mediated by acinar cell transdifferentiation and generation of nestin-positive intermediates. Development 132, 3767-3776. https://doi.org/10.1242/dev.01925

117. Merrell, A.J., Stanger, B.Z., 2016. Adult Cell Plasticity In Vivo: Trans-differentiation is Back in Style. Nat Rev Mol Cell Biol. 17, 413-425. https://doi.org/10.1038/nrm.2016.24.Adult

118. Mikkelsen, T.S., Hanna, J., Zhang, X., Ku, M., Wernig, M., Schorderet, P., Bernstein, B.E., Jaenisch, R., Lander, E.S., Meissner, A., 2008. Dissecting direct reprogramming through integrative genomic analysis. Nature 454, 49-55. https://doi.org/10.1038/nature07056

119. Miller, R.A., Ruddle, F.H., 1976. Pluripotent teratocarcinoma-thymus somatic cell hybrids. Cell 9, 45-55. https://doi.org/10.1016/0092-8674(76)90051-9

120. Mills, J.C., Stanger, B.Z., Sander, M., 2019. Nomenclature for cellular plasticity: are the terms as plastic as the cells themselves? EMBO J. 38, 1-5. https://doi.org/10.15252/embj.2019103148

121. Miyanari, Y., Torres-Padilla, M.-E., 2012. Control of ground-state pluripotency by allelic regulation of Nanog. Nature 483, 470-473. https://doi.org/10.1038/nature10807

122. Mizumoto, K., Sawa, H., 2007. Two $\beta$ s or not two $\beta$ s: regulation of asymmetric division by $\beta$ catenin. Trends Cell Biol. 17, 465-473.

https://doi.org/https://doi.org/10.1016/j.tcb.2007.08.004

123. Mojtahedi, M., Skupin, A., Zhou, J., Castaño, I.G., Leong-Quong, R.Y.Y., Chang, H., Trachana, K., Giuliani, A., Huang, S., 2016. Cell Fate Decision as High-Dimensional Critical State Transition. PLoS Biol. 14, 1-28. https://doi.org/10.1371/journal.pbio.2000640 
124. Molina-García, L., Lloret-Fernández, C., Cook, S.J., Kim, B., Bonnington, R.C., Sammut, M., O’Shea, J.M., Gilbert, S.P., Elliott, D.J., Hall, D.H., Emmons, S.W., Barrios, A., Poole, R.J., 2020. Direct glia-to-neuron transdifferentiation gives rise to a pair of male-specific neurons that ensure nimble male mating. Elife 9. https://doi.org/10.7554/eLife.48361

125. Moris, N., Pina, C., Arias, A.M., 2016. Transition states and cell fate decisions in epigenetic landscapes. Nat. Rev. Genet. 17, 693-703. https://doi.org/10.1038/nrg.2016.98

126. Morris, R., Sancho-Martinez, I., Sharpee, T.O., Belmonte, J.C.I., 2014. Mathematical approaches to modeling development and reprogramming. Proc. Natl. Acad. Sci. U. S. A. 111, 5076-5082. https://doi.org/10.1073/pnas.1317150111

127. Morris, S.A., 2019. The evolving concept of cell identity in the single cell era. Dev. 146, 1-5. https://doi.org/10.1242/dev.169748

128. Moss, F.P., Leblond, C.P., 1971. Satellite cells as the source of nuclei in muscles of growing rats. Anat. Rec. 170, 421-435. https://doi.org/10.1002/ar.1091700405

129. Ofenbauer, A., Tursun, B., 2019. Strategies for in vivo reprogramming. Curr. Opin. Cell Biol. 61, 9-15. https://doi.org/10.1016/j.ceb.2019.06.002

130. Ohkura, K., Suzuki, N., Ishihara, T., Katsura, I., 2003. SDF-9, a protein tyrosine phosphataselike molecule, regulates the L3/dauer developmental decision through hormonal signaling in $\mathrm{C}$. elegans. Development 130, 3237-3248. https://doi.org/10.1242/dev.00540

131. Okada, T.S., 1991. Transdifferentiation: flexibility in cell differentiation. Oxford University Press on Demand.

132. Packer, J.S., Zhu, Q., Huynh, C., Sivaramakrishnan, P., Preston, E., Dueck, H., Stefanik, D., Tan, K., Trapnell, C., Kim, J., Waterston, R.H., Murray, J.I., 2019. A lineage-resolved molecular atlas of C. Elegans embryogenesis at single-cell resolution. Science (80-. ). 365. https://doi.org/10.1126/science.aax1971

133. Parry, J.M., Sundaram, M. V., 2014. A non-cell-autonomous role for Ras signaling in C. elegans neuroblast delamination. Dev. 141, 4279-4284. https://doi.org/10.1242/dev.112045

134. Patel, D.S., Fang, L.L., Svy, D.K., Ruvkun, G., Li, W., 2008. Genetic identification of HSD-1, a conserved steroidogenic enzyme that directs larval development in Caenorhabditis elegans. Development 135, 2239-2249. https://doi.org/10.1242/dev.016972

135. Patel, T., Hobert, O., 2017. Coordinated control of terminal differentiation and restriction of cellular plasticity. Elife 6, 1-26. https://doi.org/10.7554/elife.24100

136. Pereira, L., Aeschimann, F., Wang, C., Lawson, H., Serrano-Saiz, E., Portman, D.S., Großhans, H., Hobert, O., 2019. Timing mechanism of sexually dimorphic nervous system differentiation. Elife 8. https://doi.org/10.7554/eLife.42078

137. Pereira, L., Kratsios, P., Serrano-Saiz, E., Sheftel, H., Mayo, A.E., Hall, D.H., White, J.G., LeBoeuf, B., Garcia, L.R., Alon, U., Hobert, O., 2015a. A cellular and regulatory map of the cholinergic nervous system of C. elegans. Elife 4. https://doi.org/10.7554/eLife.12432 
138. Pereira, L., Kratsios, P., Serrano-Saiz, E., Sheftel, H., Mayo, A.E., Hall, D.H., White, J.G., LeBoeuf, B., Garcia, L.R., Alon, U., Hobert, O., 2015b. A cellular and regulatory map of the cholinergic nervous system of C. elegans. Elife 4. https://doi.org/10.7554/eLife.12432

139. Pereira, R.F., Halford, K.W., O’Hara, M.D., Leeper, D.B., Sokolov, B.P., Pollard, M.D., Bagasra, O., Prockop, D.J., 1995. Cultured adherent cells from marrow can serve as longlasting precursor cells for bone, cartilage, and lung in irradiated mice. Proc. Natl. Acad. Sci. U. S. A. 92, 4857-4861. https://doi.org/10.1073/pnas.92.11.4857

140. Phillips, B.T., Kimble, J., 2009. A new look at TCF and beta-catenin through the lens of a divergent C. elegans Wnt pathway. Dev. Cell 17, 27-34.

https://doi.org/10.1016/j.devcel.2009.07.002

141. Pina, C., Fugazza, C., Tipping, A.J., Brown, J., Soneji, S., Teles, J., Peterson, C., Enver, T., 2012. Inferring rules of lineage commitment in haematopoiesis. Nat. Cell Biol. 14, 287-294. https://doi.org/10.1038/ncb2442

142. Plikus, M. V, Guerrero-Juarez, C.F., Ito, M., Li, Y.R., Dedhia, P.H., Zheng, Y., Shao, M., Gay, D.L., Ramos, R., Hsi, T.-C., Oh, J.W., Wang, X., Ramirez, A., Konopelski, S.E., Elzein, A., Wang, A., Supapannachart, R.J., Lee, H.-L., Lim, C.H., Nace, A., Guo, A., Treffeisen, E., Andl, T., Ramirez, R.N., Murad, R., Offermanns, S., Metzger, D., Chambon, P., Widgerow, A.D., Tuan, T.-L., Mortazavi, A., Gupta, R.K., Hamilton, B.A., Millar, S.E., Seale, P., Pear, W.S., Lazar, M.A., Cotsarelis, G., 2017. Regeneration of fat cells from myofibroblasts during wound healing. Science 355, 748-752. https://doi.org/10.1126/science.aai8792

143. Polo, J.M., Anderssen, E., Walsh, R.M., Schwarz, B.A., Nefzger, C.M., Lim, S.M., Borkent, M., Apostolou, E., Alaei, S., Cloutier, J., Bar-Nur, O., Cheloufi, S., Stadtfeld, M., Figueroa, M.E., Robinton, D., Natesan, S., Melnick, A., Zhu, J., Ramaswamy, S., Hochedlinger, K., 2012. A Molecular Roadmap of Reprogramming Somatic Cells into iPS Cells. Cell 151, 16171632. https://doi.org/10.1016/j.cell.2012.11.039

144. Priess, J.R., 2005. Notch signaling in the C. elegans embryo. WormBook 1-16. https://doi.org/10.1895/wormbook.1.4.1

145. Priess, J.R., Thomson, J.N., 1987. Cellular interactions in early C. elegans embryos. Cell 48, 241-250. https://doi.org/https://doi.org/10.1016/0092-8674(87)90427-2

146. Qian, L., Huang, Y., Spencer, C.I., Foley, A., Vedantham, V., Liu, L., Conway, S.J., Fu, J., Srivastava, D., 2012. In vivo reprogramming of murine cardiac fibroblasts into induced cardiomyocytes. Nature 485, 593-598. https://doi.org/10.1038/nature11044

147. Rebhahn, J.A., Deng, N., Sharma, G., Livingstone, A.M., Huang, S., Mosmann, T.R., 2014. An animated landscape representation of CD4+ T-cell differentiation, variability, and plasticity: Insights into the behavior of populations versus cells. Eur. J. Immunol. 44, 22162229. https://doi.org/10.1002/eji.201444645

148. Red-Horse, K., Ueno, H., Weissman, I.L., Krasnow, M., 2010. Coronary arteries form by developmental reprogramming of venous cellsNIH Public Access. Nat Immunol 464, 549-553. https://doi.org/10.1038/nature08873.Coronary 
149. Richard, J.P., Zuryn, S., Fischer, N., Pavet, V., Vaucamps, N., Jarriault, S., 2011. Direct in vivo cellular reprogramming involves transition through discrete, non-pluripotent steps. Development 138, 1483-1492. https://doi.org/10.1242/dev.063115

150. Riddle, M.R., Misty R., Spickard, E.A., Jevince, A., Nguyen, K.C.Q., Hall, D.H., Joshi, P.M., Rothman, J.H., 2016. Transorganogenesis and transdifferentiation in C. elegans are dependent on differentiated cell identity. Dev. Biol. 420, 136-147.

https://doi.org/10.1016/j.ydbio.2016.09.020

151. Riddle, M.R., Weintraub, A., Nguyen, K.C.Q., Hall, D.H., Rothman, J.H., 2013. Transdifferentiation and remodeling of post-embryonic $\mathrm{C}$. elegans cells by a single transcription factor. Development 140, 4844-4849. https://doi.org/10.1242/dev.103010

152. Rodríguez-Ubreva, J., Ciudad, L., Gómez-Cabrero, D., Parra, M., Bussmann, L.H., di Tullio, A., Kallin, E.M., Tegnér, J., Graf, T., Ballestar, E., 2012. Pre-B cell to macrophage transdifferentiation without significant promoter DNA methylation changes. Nucleic Acids Res. 40, 1954-1968. https://doi.org/10.1093/nar/gkr1015

153. Rose, L., Gonczy, P., 2014. Polarity establishment, asymmetric division and segregation of fate determinants in early C. elegans embryos. WormBook 1-43. https://doi.org/10.1895/wormbook.1.30.2

154. Rothman, J., Jarriault, S., 2019. Developmental plasticity and cellular reprogramming in caenorhabditis elegans. Genetics 213, 723-757. https://doi.org/10.1534/genetics.119.302333

155. Sallee, M.D., Littleford, H.E., Greenwald, I., 2017. A bHLH Code for Sexually Dimorphic Form and Function of the C. elegans Somatic Gonad. Curr. Biol. 27, 1853-1860.e5. https://doi.org/10.1016/j.cub.2017.05.059

156. Sammut, M., Cook, S.J., Nguyen, K.C.Q., Felton, T., Hall, D.H., Emmons, S.W., Poole, R.J., Barrios, A., 2015. Glia-derived neurons are required for sex-specific learning in C. elegans. Nature 526, 385-390. https://doi.org/10.1038/nature15700

157. Sawa, H., Korswagen, H.C., 2013. Wnt signaling in C. elegans. WormBook 1-30. https://doi.org/10.1895/wormbook.1.7.2

158. Schierenberg, E., 1984. Altered cell-division rates after laser-induced cell fusion in nematode embryos. Dev. Biol. 101, 240-245. https://doi.org/https://doi.org/10.1016/00121606(84)90136-2

159. Schroeder, N.E., Androwski, R.J., Rashid, A., Lee, H., Lee, J., Barr, M.M., 2013. DauerSpecific Dendrite Arborization in C. elegans Is Regulated by KPC-1/Furin. Curr. Biol. 23, 1527-1535. https://doi.org/10.1016/j.cub.2013.06.058

160. Schuster, E., McElwee, J.J., Tullet, J.M.A., Doonan, R., Matthijssens, F., Reece-Hoyes, J.S., Hope, I.A., Vanfleteren, J.R., Thornton, J.M., Gems, D., 2010. DamID in C. elegans reveals longevity-associated targets of DAF-16/FoxO. Mol. Syst. Biol. 6, 399. https://doi.org/10.1038/msb.2010.54 
161. Selman, K., Kafatos, F.C., 1974. Transdifferentiation in the labial gland of silk moths: is DNA required for cellular metamorphosis? Cell Differ. 3, 81-94. https://doi.org/10.1016/00456039(74)90030-x

162. Serizay, J., Dong, Y., Jänes, J., Chesney, M., Cerrato, C., Ahringer, J., 2020. Distinctive regulatory architectures of germline-active and somatic genes in C. elegans. Genome Res. 30, 1752-1765. https://doi.org/10.1101/gr.265934.120

163. Serrano-Saiz, E., Oren-Suissa, M., Bayer, E.A., Hobert, O., 2017a. Sexually Dimorphic Differentiation of a C. elegans Hub Neuron Is Cell Autonomously Controlled by a Conserved Transcription Factor. Curr. Biol. 27, 199-209. https://doi.org/10.1016/j.cub.2016.11.045

164. Serrano-Saiz, E., Pereira, L., Gendrel, M., Aghayeva, U., Bhattacharya, A., Howell, K., Garcia, L.R., Hobert, O., 2017b. A Neurotransmitter Atlas of the Caenorhabditis elegans Male Nervous System Reveals Sexually Dimorphic Neurotransmitter Usage. Genetics 206, 12511269. https://doi.org/10.1534/genetics.117.202127

165. Sha, K., Gu, S.G., Pantalena-Filho, L.C., Goh, A., Fleenor, J., Blanchard, D., Krishna, C., Fire, A., 2010. Distributed probing of chromatin structure in vivo reveals pervasive chromatin accessibility for expressed and non-expressed genes during tissue differentiation in C. elegans. BMC Genomics 11, 465. https://doi.org/10.1186/1471-2164-11-465

166. Shearn, A., Davis, K.T., Hersperger, E., 1978. Transdetermination of Drosophila imaginal discs cultured in vitro. Dev. Biol. 65, 536-540. https://doi.org/https://doi.org/10.1016/00121606(78)90049-0

167. Shemer, G., Podbilewicz, B., 2002. LIN-39/Hox triggers cell division and represses EFF1/fusogen-dependent vulval cell fusion. Genes Dev. 16, 3136-3141. https://doi.org/10.1101/gad.251202

168. Shparberg, R.A., Glover, H.J., Morris, M.B., 2019. Embryoid Body Differentiation of Mouse Embryonic Stem Cells into Neurectoderm and Neural Progenitors. Methods Mol. Biol. 2029, 273-285. https://doi.org/10.1007/978-1-4939-9631-5_21

169. Slack, J.M.W., 1991. From Egg to Embryo: Regional Specification in Early Development, 2nd ed, Developmental and Cell Biology Series. Cambridge University Press, Cambridge. https://doi.org/DOI: 10.1017/CBO9780511525322

170. Song, G., Pacher, M., Balakrishnan, A., Yuan, Q., Tsay, H.-C., Yang, D., Reetz, J., Brandes, S., Dai, Z., Pützer, B.M., Araúzo-Bravo, M.J., Steinemann, D., Luedde, T., Schwabe, R.F., Manns, M.P., Schöler, H.R., Schambach, A., Cantz, T., Ott, M., Sharma, A.D., 2016. Direct Reprogramming of Hepatic Myofibroblasts into Hepatocytes In Vivo Attenuates Liver Fibrosis. Cell Stem Cell 18, 797-808. https://doi.org/10.1016/j.stem.2016.01.010

171. Song, Q., Liu, H., Zhen, H., Zhao, B., 2020. Autophagy and its role in regeneration and remodeling within invertebrate. Cell Biosci. 10, 1-16. https://doi.org/10.1186/s13578-02000467-3

172. Sparacio, A.P., Trojanowski, N.F., Snetselaar, K., Nelson, M.D., Raizen, D.M., 2020. Teething during sleep: Ultrastructural analysis of pharyngeal muscle and cuticular grinder during the 
molt in Caenorhabditis elegans. PLoS One 15, e0233059.

https://doi.org/10.1371/journal.pone.0233059

173. Spickard, E.A., Joshi, P.M., Rothman, J.H., 2018. The multipotency-to-commitment transition in Caenorhabditis elegans - implications for reprogramming from cells to organs. FEBS Lett. 592, 838-851. https://doi.org/10.1002/1873-3468.12977

174. Sprecher, S.G., Desplan, C., 2008. Switch of rhodopsin expression in terminally differentiated Drosophila sensory neurons. Nature 454, 533-537. https://doi.org/10.1038/nature07062

175. Srivastava, D., DeWitt, N., 2016. In Vivo Cellular Reprogramming: The Next Generation. Cell 166, 1386-1396. https://doi.org/10.1016/j.cell.2016.08.055

176. Stevens, N.M., 1909. Further studies on the chromosomes of the Coleoptera. J. Exp. Zool. 6, 101-113. https://doi.org/https://doi.org/10.1002/jez.1400060104

177. Stone, C.E., Hall, D.H., Sundaram, M. V, 2009. Lipocalin signaling controls unicellular tube development in the Caenorhabditis elegans excretory system. Dev. Biol. 329, 201-211. https://doi.org/10.1016/j.ydbio.2009.02.030

178. Sulston, J.E., Albertson, D.G., Thomson, J.N., 1980. The Caenorhabditis elegans male: postembryonic development of nongonadal structures. Dev. Biol. 78, 542-576. https://doi.org/10.1016/0012-1606(80)90352-8

179. Sulston, J.E., Horvitz, H.R., 1977. Post-embryonic cell lineages of the nematode, Caenorhabditis elegans. Dev. Biol. 56, 110-156. https://doi.org/10.1016/0012-1606(77)901580

180. Sulston, J.E., Schierenberg, E., White, J.G., Thomson, J.N., 1983. The embryonic cell lineage of the nematode Caenorhabditis elegans. Dev. Biol. https://doi.org/10.1016/00121606(83)90201-4

181. Sundaram, M. V, Buechner, M., 2016. The Caenorhabditis elegans Excretory System: A Model for Tubulogenesis, Cell Fate Specification, and Plasticity. Genetics 203, 35-63. https://doi.org/10.1534/genetics.116.189357

182. Takahashi, K., Tanabe, K., Ohnuki, M., Narita, M., Ichisaka, T., Tomoda, K., Yamanaka, S., 2007. Induction of pluripotent stem cells from adult human fibroblasts by defined factors. Cell 131, 861-872. https://doi.org/10.1016/j.cell.2007.11.019

183. Takahashi, K., Yamanaka, S., 2006. Induction of pluripotent stem cells from mouse embryonic and adult fibroblast cultures by defined factors. Cell 126, 663-676. https://doi.org/10.1016/j.cell.2006.07.024

184. Tarlow, B.D., Pelz, C., Naugler, W.E., Wakefield, L., Wilson, E.M., Finegold, M.J., Grompe, M., 2014. Bipotential Adult Liver Progenitors Are Derived from Chronically Injured Mature Hepatocytes. Cell Stem Cell 15, 605-618. https://doi.org/10.1016/j.stem.2014.09.008

185. Taylor, S.R., Santpere, G., Reilly, M., Glenwinkel, L., Poff, A., McWhirter, R., Xu, C., Weinreb, A., Basavaraju, M., Cook, S.J., Barrett, A., Abrams, A., Vidal, B., Cros, C., Rafi, I., Sestan, N., Hammarlund, M., Hobert, O., Miller, D.M., 2019. Expression profiling of the 
mature C. elegans nervous system by single-cell RNA-Sequencing. bioRxiv 737577. https://doi.org/10.1101/737577

186. Thomas, J.H., 1994. The mind of a worm. Science 264, 1698-1699. https://doi.org/10.1126/science.7911601

187. Towbin, B.D., González-Aguilera, C., Sack, R., Gaidatzis, D., Kalck, V., Meister, P., Askjaer, P., Gasser, S.M., 2012. Step-wise methylation of histone H3K9 positions heterochromatin at the nuclear periphery. Cell 150, 934-947. https://doi.org/10.1016/j.cell.2012.06.051

188. Treutlein, B., Lee, Q.Y., Camp, J.G., Mall, M., Koh, W., Shariati, S.A.M., Sim, S., Neff, N.F., Skotheim, J.M., Wernig, M., Quake, S.R., 2016. Dissecting direct reprogramming from fibroblast to neuron using single-cell RNA-seq. Nature 534, 391-395. https://doi.org/10.1038/nature18323

189. Tursun, B., Patel, T., Kratsios, P., Hobert, O., 2011. Direct conversion of C. elegans germ cells into specific neuron types. Science 331, 304-308. https://doi.org/10.1126/science.1199082

190. Vazin, T., Freed, W.J., 2010. Human embryonic stem cells: Derivation, culture, and differentiation: A review. Restor. Neurol. Neurosci. 28, 589-603. https://doi.org/10.3233/RNN-2010-0543

191. Velten, L., Haas, S.F., Raffel, S., Blaszkiewicz, S., Islam, S., Hennig, B.P., Hirche, C., Lutz, C., Buss, E.C., Nowak, D., Boch, T., Hofmann, W.-K., Ho, A.D., Huber, W., Trumpp, A., Essers, M.A.G., Steinmetz, L.M., 2017. Human haematopoietic stem cell lineage commitment is a continuous process. Nat. Cell Biol. 19, 271-281. https://doi.org/10.1038/ncb3493

192. Vierbuchen, T., Ostermeier, A., Pang, Z.P., Kokubu, Y., Thomas, C., Wernig, M., 2010. Direct conversion of fibroblasts to functional neurons by defined factors. Nature 463, 1035-1041.

193. Virchow, R., 1886. Congrès périodique international des sciences médicales. 8ème session. Copenhague, 1884. Compte rendu. Copenhagen.

194. Waddington, C.H., 1957. The Strategy of the Genes, 1st Editio. ed.

195. Walthall, W.W., Li, L., Plunkett, J.A., Hsu, C.Y., 1993. Changing synaptic specificities in the nervous system of Caenorhabditis elegans: differentiation of the DD motoneurons. J.

Neurobiol. 24, 1589-1599. https://doi.org/10.1002/neu.480241204

196. Wang, J., Xu, L., Wang, E., Huang, S., 2010. The potential landscape of genetic circuits imposes the arrow of time in stem cell differentiation. Biophys. J. 99, 29-39. https://doi.org/10.1016/j.bpj.2010.03.058

197. Wang, J., Zhang, K., Xu, L., Wang, E., 2011. Quantifying the Waddington landscape and biological paths for development and differentiation. Proc. Natl. Acad. Sci. U. S. A. 108, 8257-8262. https://doi.org/10.1073/pnas.1017017108

198. Weintraub, H., Davis, R., Tapscott, S., Thayer, M., Krause, M., Benezra, R., Blackwell, T.K., Turner, D., Rupp, R., Hollenberg, S., et al., 1991. The myoD gene family: nodal point during specification of the muscle cell lineage. Science 251, 761 LP - 766.

https://doi.org/10.1126/science.1846704 
199. Weiss, P.A., 1973. Differentiation and its Three Facets: Facts, Terms and Meaning. Differentiation 1, 3-10. https://doi.org/https://doi.org/10.1111/j.1432-0436.1973.tb00098.x

200. What Is Your Conceptual Definition of "Cell Type" in the Context of a Mature Organism?, 2017. Cell Syst. 4, 255-259. https://doi.org/10.1016/j.cels.2017.03.006

201. White, J.G., 1988. The Anatomy In The nematode C. elegans. Cold Spring Harbor Laboratory Press, Cold Spring Harbor, New York.

202. White, J.G., Southgate, E., Thomson, J.N., Brenner, S., 1986. The structure of the nervous system of the nematode Caenorhabditis elegans. Philos. Trans. R. Soc. London. Ser. B, Biol. Sci. 314, 1-340. https://doi.org/10.1098/rstb.1986.0056

203. White, J.G., Southgate, E., Thomson, J.N., Brenner, S., 1976. The structure of the ventral nerve cord of Caenorhabditis elegans. Philos. Trans. R. Soc. London. Ser. B, Biol. Sci. 275, 327-348. https://doi.org/10.1098/rstb.1976.0086

204. Wilson, E.B., 1906. Mendelian inheritance and the purity of the gametes. Science 23, 112 LP 113. https://doi.org/10.1126/science.23.577.112-a

205. Worley, M.I., Setiawan, L., Hariharan, I.K., 2012. Regeneration and transdetermination in Drosophila imaginal discs. Annu. Rev. Genet. 46, 289-310. https://doi.org/10.1146/annurevgenet-110711-155637

206. Xu, L., Zhang, K., Wang, J., 2014. Exploring the mechanisms of differentiation, dedifferentiation, reprogramming and transdifferentiation. PLoS One 9. https://doi.org/10.1371/journal.pone.0105216

207. Yamada, T., 1977. Control mechanisms in cell-type conversion in newt lens regeneration. Monogr. Dev. Biol. 13, 1-126.

208. Yanger, K., Zong, Y., Maggs, L.R., Shapira, S.N., Maddipati, R., Aiello, N.M., Thung, S.N., Wells, R.G., Greenbaum, L.E., Stanger, B.Z., 2013. Robust cellular reprogramming occurs spontaneously during liver regeneration. Genes Dev. 27, 719-724.

https://doi.org/10.1101/gad.207803.112

209. Yin, H., Price, F., Rudnicki, M.A., 2013. Satellite cells and the muscle stem cell niche. Physiol. Rev. 93, 23-67. https://doi.org/10.1152/physrev.00043.2011

210. Yuzyuk, T., Fakhouri, T.H.I., Kiefer, J., Mango, S.E., 2009. The Polycomb Complex Protein mes-2/E(z) Promotes the Transition from Developmental Plasticity to Differentiation in C. elegans Embryos. Dev. Cell 16, 699-710.

https://doi.org/https://doi.org/10.1016/j.devcel.2009.03.008

211. Zemmour, D., Zilionis, R., Kiner, E., Klein, A.M., Mathis, D., Benoist, C., 2018. Single-cell gene expression reveals a landscape of regulatory $\mathrm{T}$ cell phenotypes shaped by the TCR. Nat. Immunol. 19, 291-301. https://doi.org/10.1038/s41590-018-0051-0

212. Zhang, R., Han, P., Yang, H., Ouyang, K., Lee, D., Lin, Y.-F., Ocorr, K., Kang, G., Chen, J., Stainier, D.Y.R., Yelon, D., Chi, N.C., 2013. In vivo cardiac reprogramming contributes to zebrafish heart regeneration. Nature 498, 497-501. https://doi.org/10.1038/nature12322 
213. Zhou, J.X., Brusch, L., Huang, S., 2011. Predicting pancreas cell fate decisions and reprogramming with a hierarchical multi-attractor model. PLoS One 6, e14752. https://doi.org/10.1371/journal.pone.0014752

214. Zhou, Y., Wang, L., Vaseghi, H.R., Liu, Z., Lu, R., Alimohamadi, S., Yin, C., Fu, J.-D., Wang, G.G., Liu, J., Qian, L., 2016. Bmi1 Is a Key Epigenetic Barrier to Direct Cardiac Reprogramming. Cell Stem Cell 18, 382-395. https://doi.org/10.1016/j.stem.2016.02.003

215. Zhu, J., Fukushige, T., McGhee, J.D., Rothman, J.H., 1998. Reprogramming of early embryonic blastomeres into endodermal progenitors by a Caenorhabditis elegans GATA factor. Genes Dev. 12, 3809-3814. https://doi.org/10.1101/gad.12.24.3809

216. zur Strassen, O., 1896. Embryonalentwickelung der Ascaris megalocephala. Arch. für Entwicklungsmechanik der Org. 3, 133-190. https://doi.org/10.1007/BF02152847

217. Zuryn, S., Ahier, A., Portoso, M., White, E.R., Morin, M.C., Margueron, R., Jarriault, S., 2014. Sequential histone-modifying activities determine the robustness of transdifferentiation. Science 345, 826-829. https://doi.org/10.1126/science.1255885

218. Zuryn, S., Le Gras, S., Jamet, K., Jarriault, S., 2010. A Strategy for Direct Mapping and Identification of Mutations by Whole-Genome Sequencing. Genetics 186, 427 LP - 430. https://doi.org/10.1534/genetics.110.119230

219. Zwilling, E., 1963. Formation of endoderm from ectoderm in cordylophora. Biol. Bull. 124, 368-378. https://doi.org/10.2307/1539486

\section{Box $1-$ C. elegans as a model to study cellular plasticity}

Following its development as a model organism by Sydney Brenner (Brenner, 1974), C. elegans has proved a valuable tool to study cellular plasticity. Two properties make it especially appealing for this. First, multiple tools for deep genetic analyses allow to connect phenome and genome, including a fully sequenced genome, a public mutants library, Next Generation Sequencing technologies, random mutagenesis and genome editing or RNA and protein targeting approaches (Doitsidou et al., 2010; Kutscher and Shaham, 2014; Lesa, 2006; Zuryn et al., 2010). Second, $C$. elegans exhibits eutely, a fixed number of somatic cells at adulthood: 959 somatic cells in hermaphrodites and 1031 in males. The somatic cell lineage of the worm has been well-described and is essentially invariant and stereotyped in space and time (Sammut et al., 2015; Sulston et al., 1983, 1980; Sulston and Horvitz, 1977). Consequently, every single cell can be assigned a specific name (e.g. V6p, U) or a lineage code (e.g. ABarpapa). Therefore, assessing the ancestry-to-descendent 
relationship between cells - which is mandatory when studying cellular plasticity in vivo - can be done with ease, and individual cells can be visualised in live animals.

The ability to perform single-cell omics has long been a vertebrate system privilege, owing to the very low cell number in each $C$. elegans tissue, and the absence of nematode cell lines. Today, these omic approaches are getting more common in C. elegans, including ChIP Seq, DAM ID or ATAC Seq (Araya et al., 2014; Durham et al., 2020; Gao et al., 2018; Gómez-Saldivar et al., 2020; González-Aguilera et al., 2014; Hastings et al., 2019; Jänes et al., 2018; Schuster et al., 2010; Serizay et al., 2020; Sha et al., 2010; Towbin et al., 2012). RNA-seq, and scRNA-seq in particular, have been developed in C. elegans and are beginning to allow the comparison of cellular transitions (Cao et al., 2017; Crane et al., 2015; Packer et al., 2019; Taylor and Reilly, 2019).

\section{Box 2 - Differentiation and commitment}

The process during which embryonic blastomeres adopt their final identity during development is divided into three phases called specification, determination and differentiation. The difference between a specified or a determined blastomere is how stable its fate is irrespective of its environment: specification is reversible while determination is irreversible, as classically tested through ectopic grafting and the ability to differentiate in culture. Although commitment is sometimes described as the process encompassing these two steps (Slack, 1991), we will equate commitment with determination in this review. Committed blastomeres are fated towards a specific lineage, but do not exhibit yet a differentiated cellular phenotype. Differentiation, that follows commitment, represents the actual changes in the cell intrinsic properties/phenome and results in a specific cell type with a specialised function.

\section{Box 3 - Cellular potential}


A key notion when studying cellular plasticity is the cellular potential of a cell, or range of cell types that a cell can give rise to or acquire. In an organism, some cells exhibit wider cellular potential than others while many exhibit none. A cell that can generate the three embryonic layers as well as the extra-embryonic tissues is totipotent while one that can contribute to the three embryonic layers is pluripotent. Since there is no extra-embryonic tissue in C. elegans however, the highest degree of cellular potential is pluripotency. A cell that can generate several but not all cell types is multipotent. Lastly, a cell that can generate only one cell type - different from itself - is unipotent. 


\section{Figure Legends}

\section{Figure 1. Types of cellular transitions encountered in development and reprogramming. (A)}

Forms of cellular plasticity. Undifferentiated cells (blastomeres/ESCs/iPSCs) exhibit pluripotency, the highest degree of cellular potency and can be differentiated into all cell types. Tissue stem cells are only multipotent and rely on asymmetric division to maintain the stem-cell pool. Transdetermination is the swap in lineage determination of committed, undifferentiated cells, transdifferentiation is the swap in identity of differentiated cells and can occur with or without an asymmetric division. During Epithelial-Mesenchymal-Transition (EMT) epithelial cells transition to a mesenchymal identity and can be reversed through the opposite process called MesenchymalEpithelial-Transition (MET). (B) Cell states and functional tuning. Within an identity, cells can exist in different states. The different 'variation' states can arise from interaction with the environment such as the selection of immune T-cell clones unique to specific antigens. VDs and DDs are different motoneuron subtypes in C. elegans. Developmental time, governed by the heterochronic gene lin-14, acts as a cell intrinsic signal (yellow asterisk) to induce the synapse remodelling of the DD motorneurons. Their connectivity radically changes but gene expression and function remains unaltered. Thus, DD motoneurons rewiring corresponds to a change of state, referred to as functional tuning. 

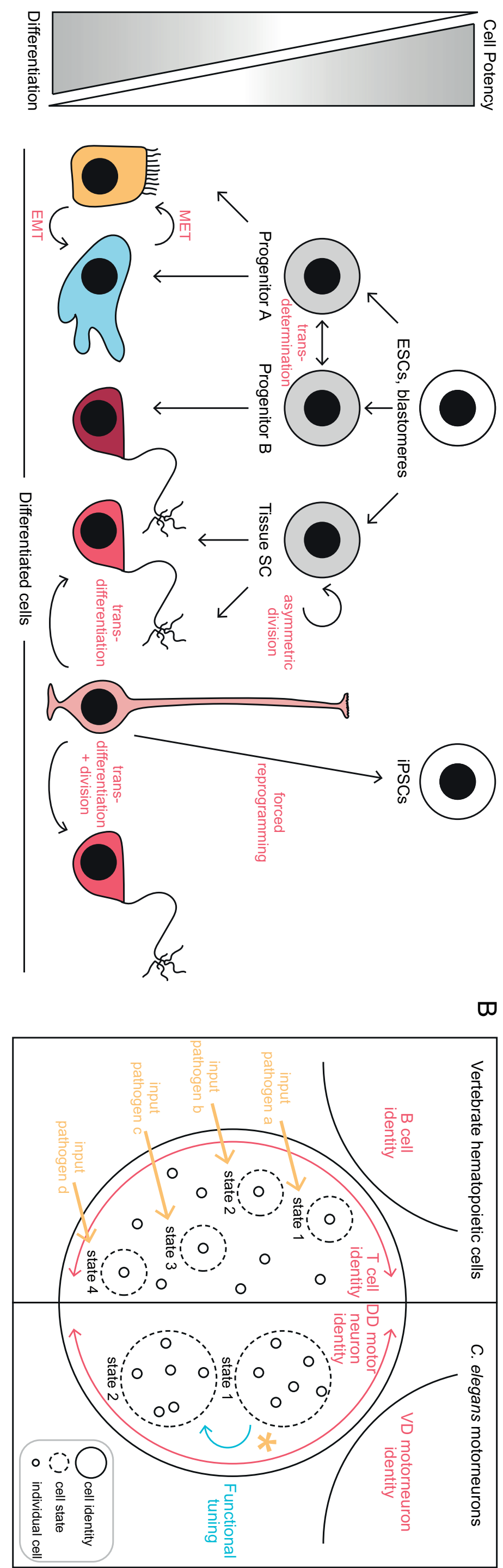
Figure 2. Epigenetic landscape, developmental trajectories and transition states. (A) The original landscape proposed by Waddington depicts continuous and smooth changes in identity (single arrow). Reproduced from The Strategy of the Genes RLE, 1st Edition by C.H., Waddington, published by Routledge. (C) George Allen \& Unwin Ltd. 1957. Reproduced by arrangement with Taylor \& Francis Group. (B) Alternative 3D depiction of epigenetic landscape. Both pluripotent and differentiated identities are represented as attractors and separated by lowstability ridges. Cells differentiate following a succession of discrete steps (multiple arrows). Pluripotent attractors appear as shallower wells, while differentiated attractors appear as deeper wells. Variation space is represented by the diameter of the well. (C-E) Non-stable transition state. (C) The non-stable transition state (TS) is defined at the cell population level as the group of cells that transition from the attractor A to the attractor B. (D) Probability distribution of the non-stable transition state in a PCA plot. (E) Changes in gene expression are gradual and the gene expression patterns of the two identities overlap as the initial identity is progressively turned down. (F-H) Metastable transition state. (F) The meta-stable transition state is defined as a minor attractor between identity A and identity B. (G) Probability distribution of the meta-stable transition state in a PCA plot. (H) i. The meta-stable TS can exhibit a combination of both identities' gene expression patterns, or ii. exhibits a distinct gene expression pattern compared to identities A and B. (C, D, F, G) The blue clouds indicate the TS. 

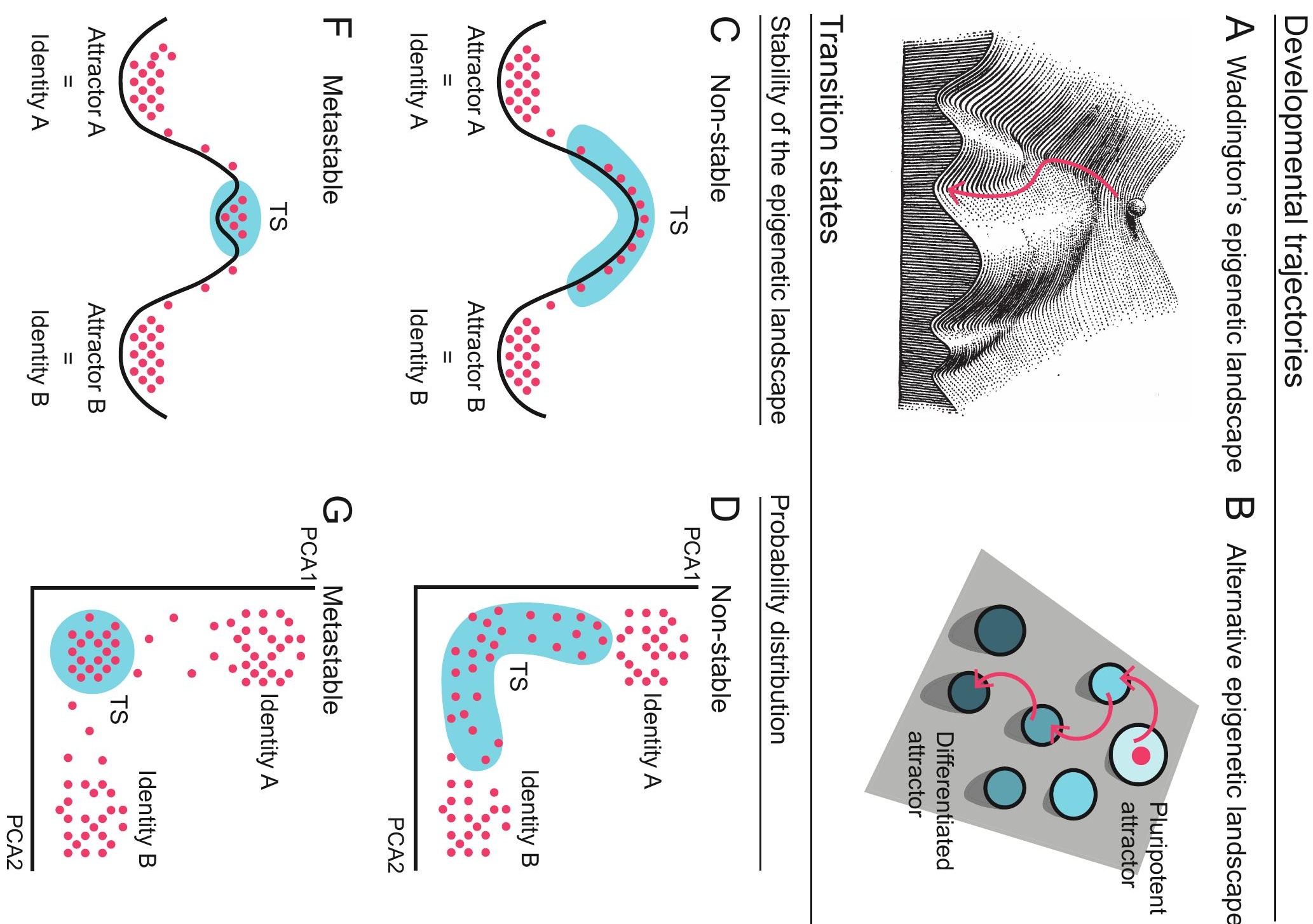

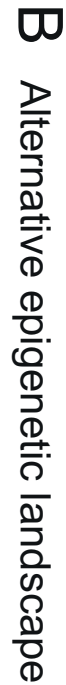

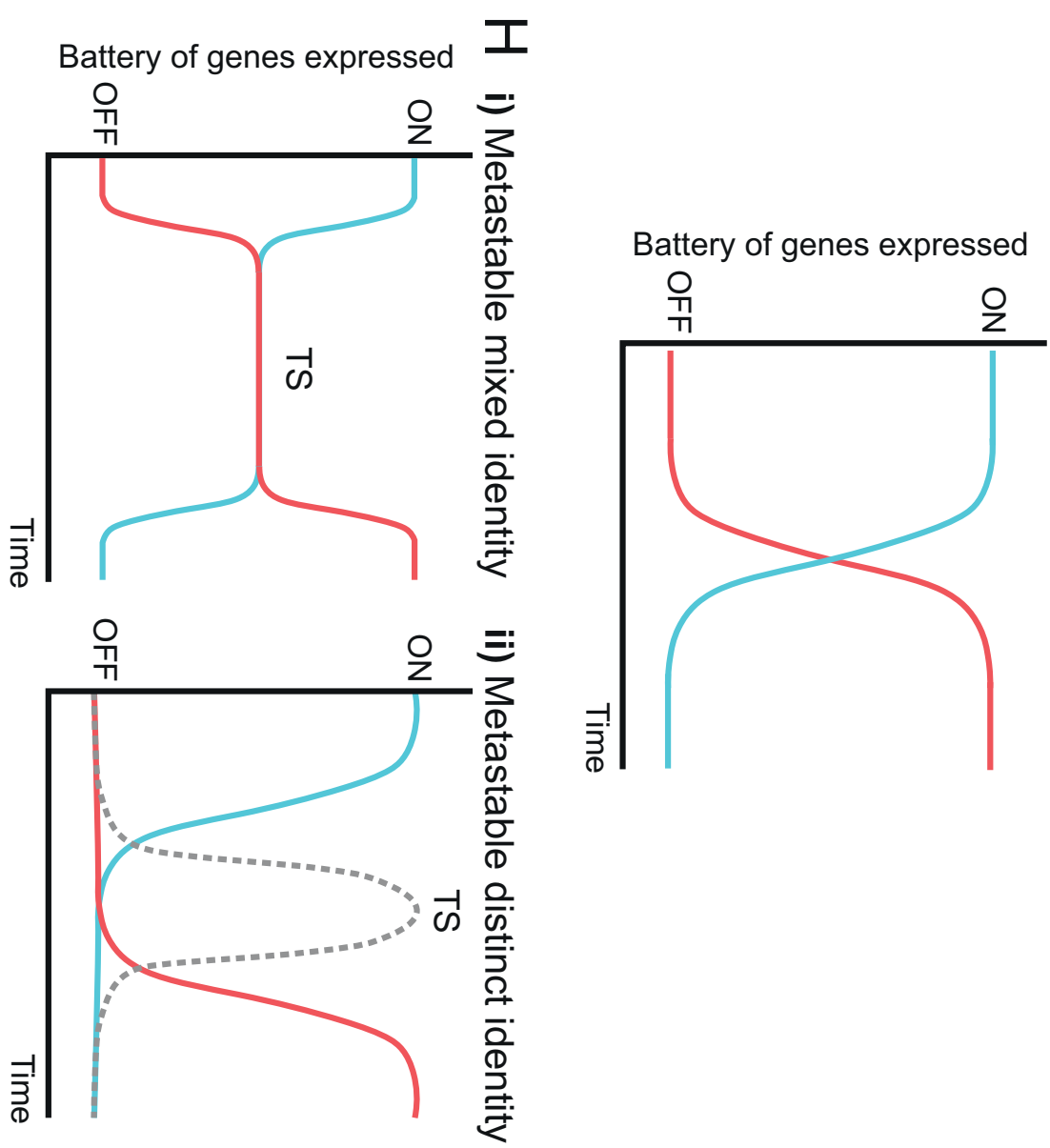


Figure 3. The atlas of natural plasticity of cell identity in C. elegans.

A) Schematic representation of known and putative natural transdifferentiation events in both sexes of the worm. Individual cells are represented as dots. Colours are used to distinguish between transdifferentiations with (blue) and without (red) a cell division, and those that await experimental validation (yellow). G1, G2, K, Y, pm6, pm7, MSaaaapa, DD1-6 and the anal depressor muscle exist as single cells. AMso, PHso1, XXX cells, the 16 seam cells, PHC, IL2, IL2D and IL2V exist as bilateral pairs in the worm, and only one side is illustrated. B) Selected examples of cellular plasticity that sit in the edges of the definition illustrate the concepts of transdetermination, functional tuning, reversibility, and the importance of establishing the original and final identities of the cells. Anterior is to the left, and ventral to the bottom. 
A Hermaphrodite $q^{\pi}$

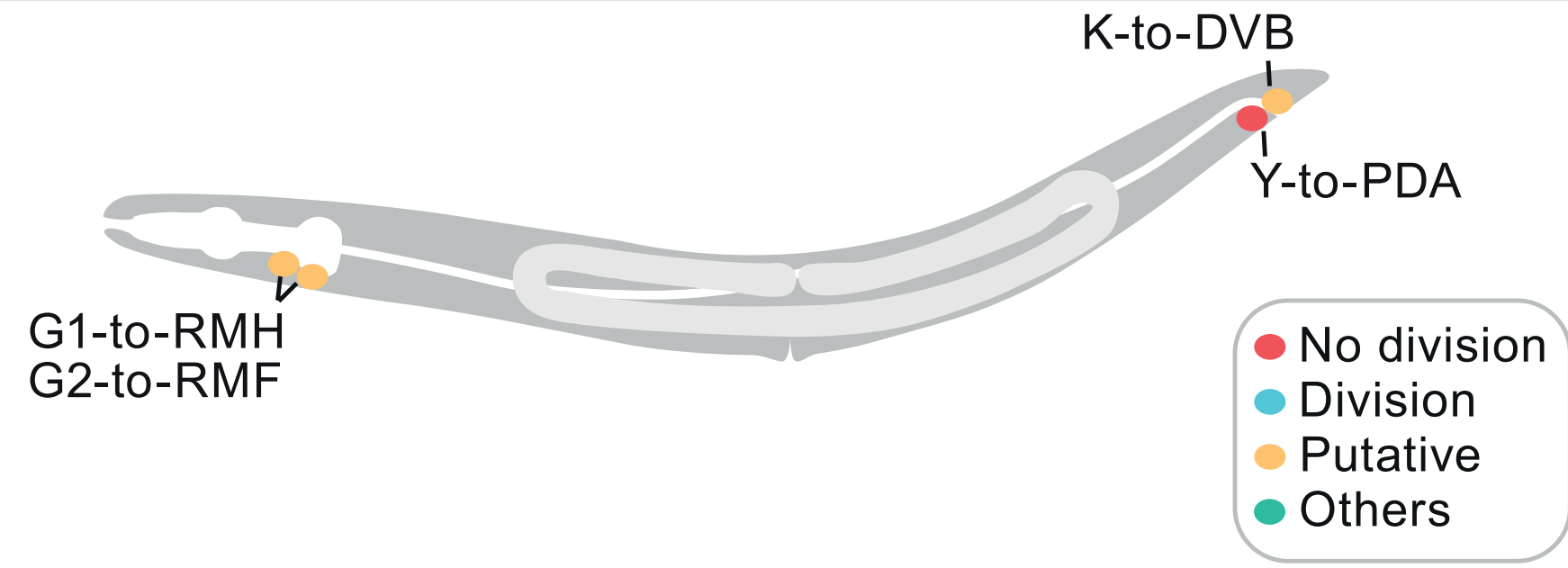

Male $0^{7}$

K-to-DVB

PHso1-to-PHD

AMso-to-MCM

I

Y-to-PDA

G1-to-RMH

G2-to-RMF

B Other forms of plasticity

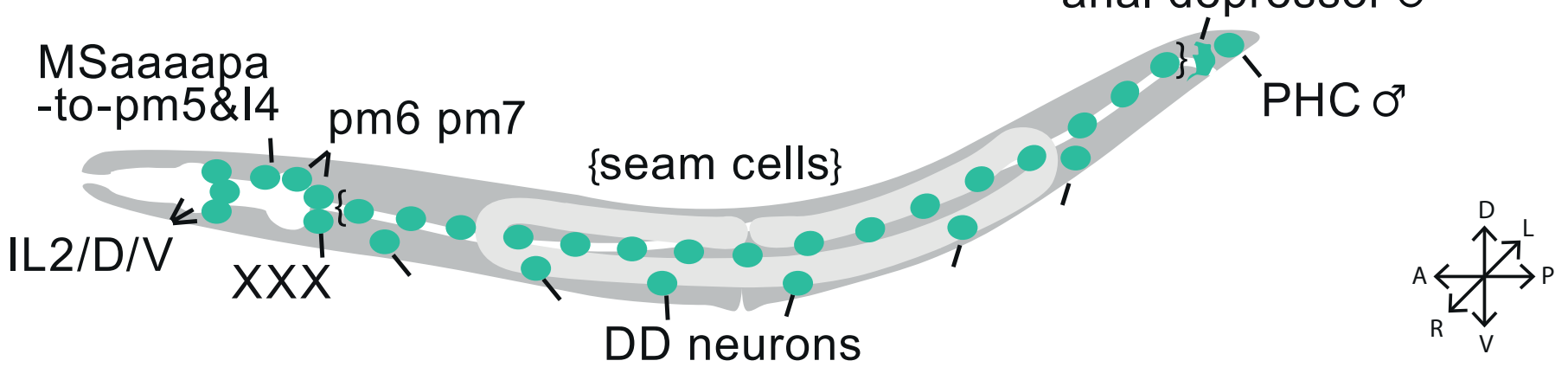


Figure 4. Transdifferentiation in the absence of cell division. Cell lineages relative to developmental time (left). Cellular paradigm and molecular regulators (right). A) Y-to-PDA transdifferentiation in hermaphrodite worms. The rectal epithelial-to-neuron transdifferentiation occurs through a succession of discrete cellular and molecular transition states. Y delaminates from the rectum at the end of L1 stage, losing its apical junctions (red) and its epithelial identity (dedifferentiation), and re-differentiates into the PDA motorneuron by the L3 stage. Different cell states have been identified based on cell morphology and molecular markers expressed: Y (epithelial markers ajm-1, dlg-1, ceh-6, peb-1, ceh-14, and rectal markers col-34, lin-26, egl-26, egl5 and $c k i-1)$, Y.0 (devoid of any rectal-epithelial and neuronal markers), Y.1 (neuronal markers unc33 and cog-1), and PDA (neuronal markers: unc-119, F25B3.3, exp-1 and ace-3/4). Different molecular players act in a sequential manner, including the chromatin-modifying NODE-like complex, SOX-2 and its downstream regulator EGL-5/HOX, and the ZTF-11/Myt11 transcription factor (de-differentiation), the histone modifier complexes SET-1 and JMJD-3.1 (de-differentiation and re-differentiation), and the transcription factor UNC-3/COE. B) PHso1-to-PHD transdifferentiation in male worms. At the early L4 stage, the pair of socket glial cells PHso1 retract their pore socket structure, and grow an anterior axon that projects towards the pre-anal ganglion region, which is a feature of the PHD sensory neurons. This process is mirrored by the concomitant downregulation of glial markers (mir-228, ptr-10, itr-1, grl-2, ztf-16 and lin-48) and upregulation of neuronal markers ( $r a b-3$, ida-1, oig-8, osm-6 and unc-17). The sex determination pathway acts cellautonomously to initiate transdifferentiation specifically in male worms, and the HLH-14/ASCL1 transcription factor is required for the production of the PHD neurons. PHsol can also divide to produce PHD1/2. 

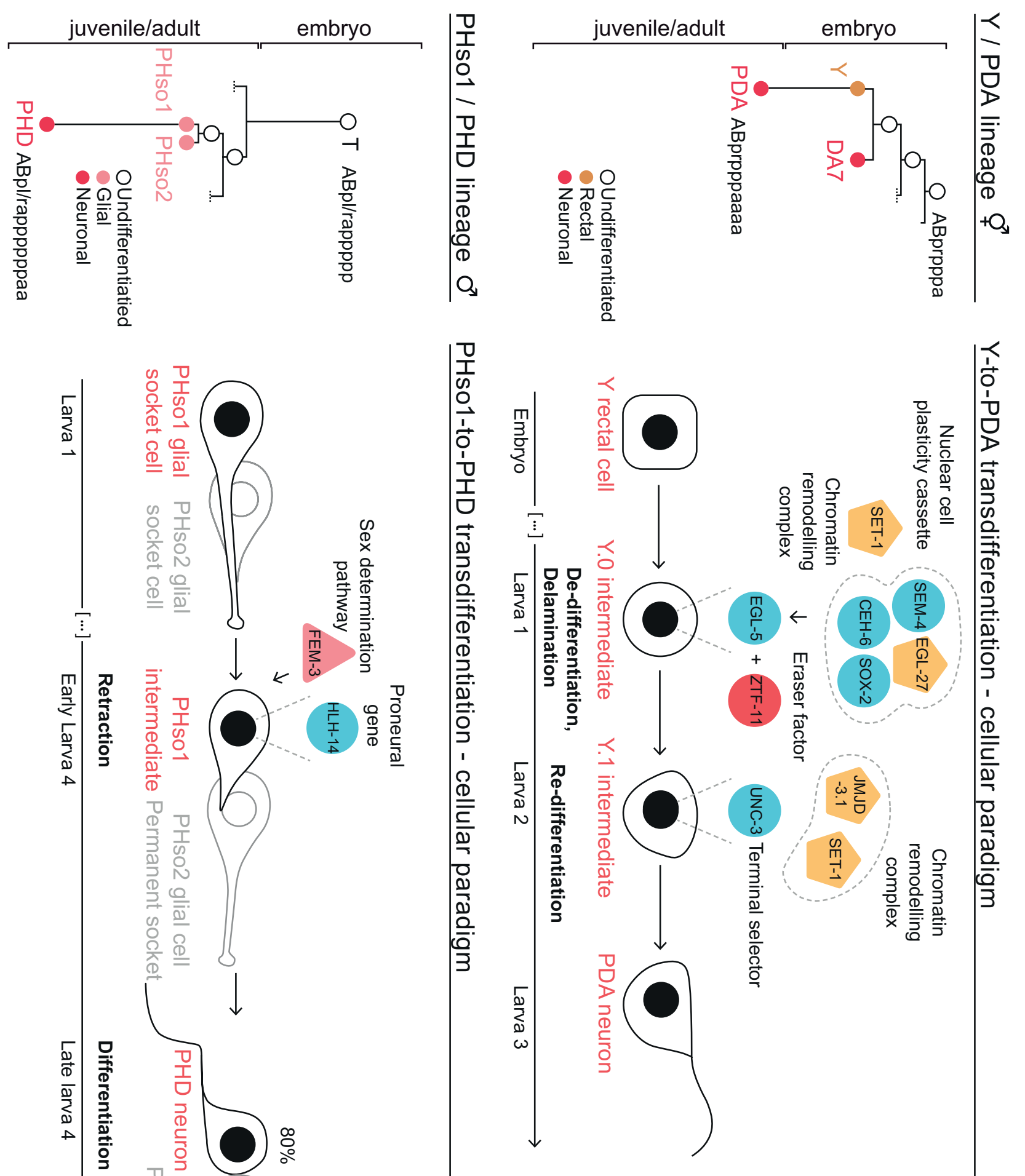
Figure 5. Transdifferentiation through a cell division. Cell lineages relative to developmental time (left). Cellular paradigm and molecular regulators (right). A) AMso-to-MCM transdifferentiation in male worms. At the early L4 stage, the pair of amphid socket glial cells AMso divide to self-renew and give rise to the pair of MCM chemosensory neuron. The AMso glial daughter expresses its original glial markers (mir-228, ptr-10, itr-1, grl-2, ztf-16 and lin-48), whereas the daughter MCM projects an axon posteriorly to the nerve ring and expresses a battery of effector neuronal genes ( $\mathrm{rab}$ 3, rgef-1, ric-19, snb-1, snt-1, unc-64, ida-1, inx-3 and nca-2). The sex determination pathway acts cell autonomously to initiate transdifferentiation specifically in male worms, and the cell cycle kinase CDK-4 is required for the production of the MCM neurons. B-D) await experimental validation to be considered bona fide transdifferentiations. B) K-to-DVB. The rectal cell $\mathrm{K}$ delaminates from the rectum at the L1 stage and divides to produce two daughter cells with asymmetric cell fates: K.a remains rectal and K.p becomes the DVB motor- and interneuron by the end of the L3 stage. The ZTF-11 transcription factor is required for the production of DVB. C) Y-to-PDA in male worms. The rectal epithelial cell Y gives rise to the PDA neuron but, differently to hermaphrodites, this involves a cell division. C) G1-to-RMH. The G1 epithelial cell forms a small unicellular tube (red) that serves as the primary excretory pore during embryogenesis and expresses epithelial markers (lin26, nnr-23, nhr-25) and the G1 marker lag-1. During the L1 larval stage, the G1 pore delaminates and loses its apical junctions, and divides symmetrically to generate the motor- and interneurons RMHL and RMHR. D) G2-to-RMF. The G2 epithelial cell divides symmetrically in the early L2 stage and the posterior daughter (G2.p) becomes the permanent excretory pore, replacing the G1 pore. The anterior daughter (G2.a) further divides symmetrically into the RMFL/R motorneurons. 
A $\underline{\text { AMso / MCM lineage } 0^{7}}$

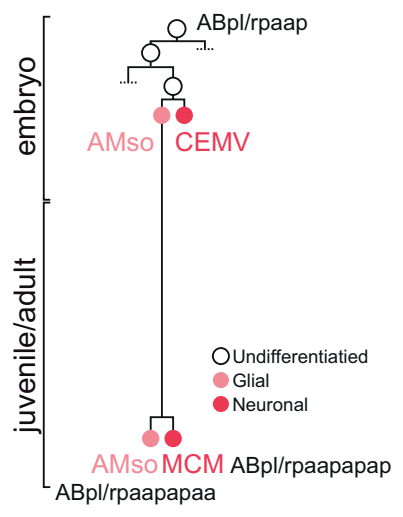

$B \underline{K} / D V B$ lineage $\overbrace{}^{7} O^{x}$

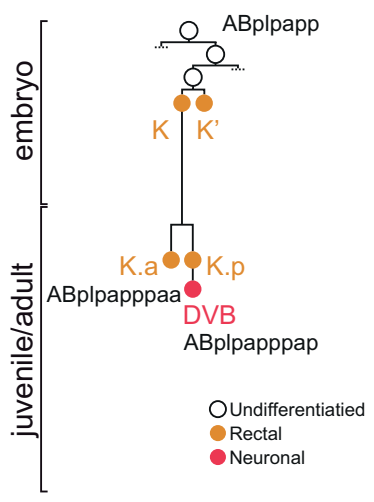

C Y / PDA lineage $\sigma^{7}$

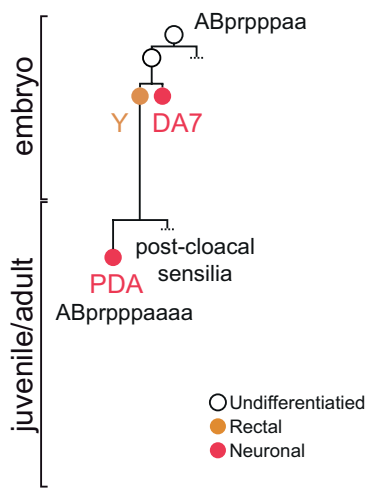

D $\underline{\text { G1 / RMH lineage } \text { Ơ⿱ }^{7} \mathrm{O}^{7}}$

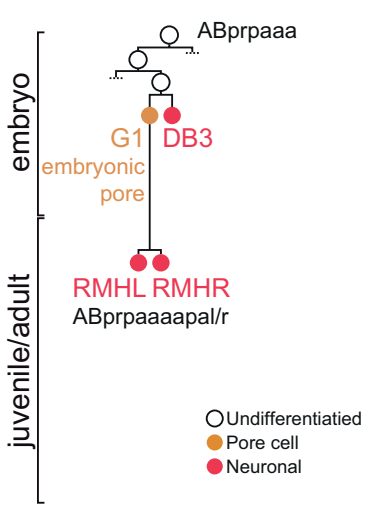

E G2/RMF lineage O $^{x} 0^{x}$

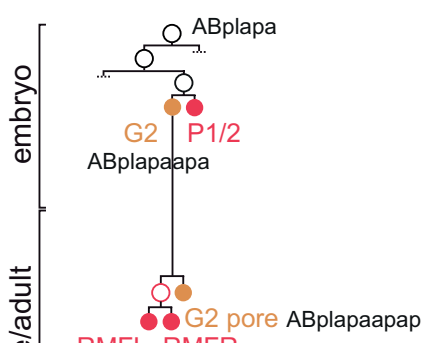

RMFL RMFR

ABplapaapaal/r

OUndifferentiatied Pore cell
Neuronal

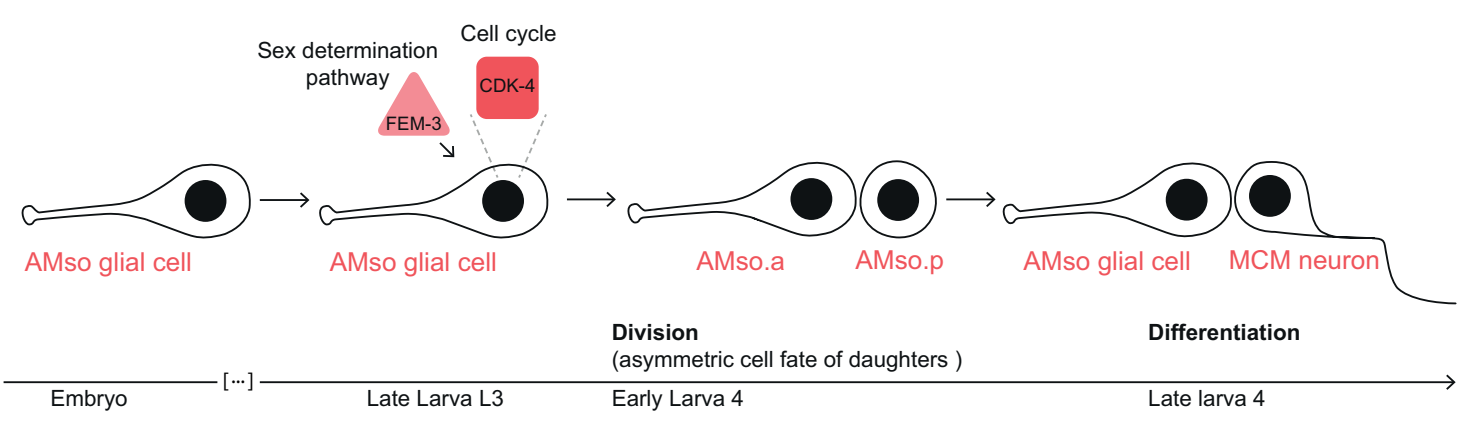

K-to-DVB transdifferentiation with a division - cellular paradigm
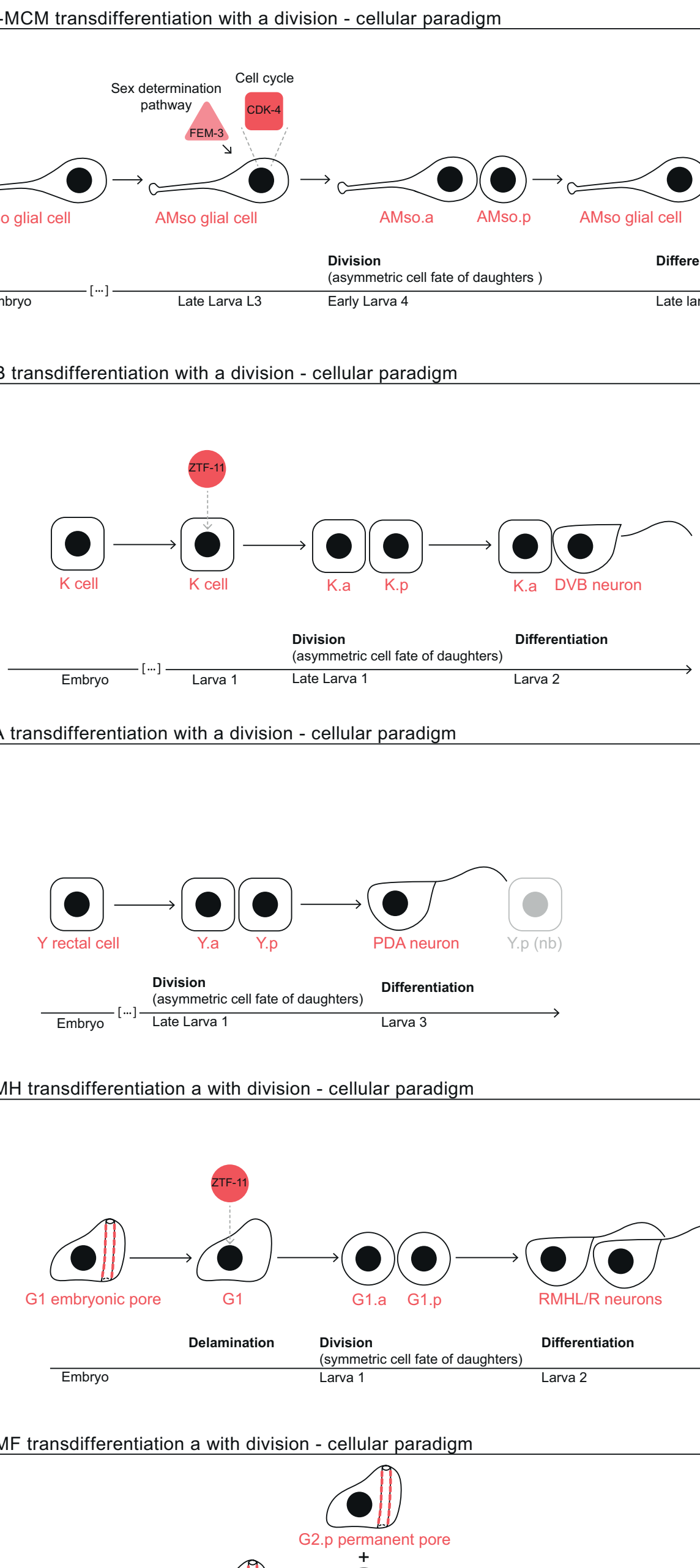

Y-to-PDA transdifferentiation with a division - cellular paradigm

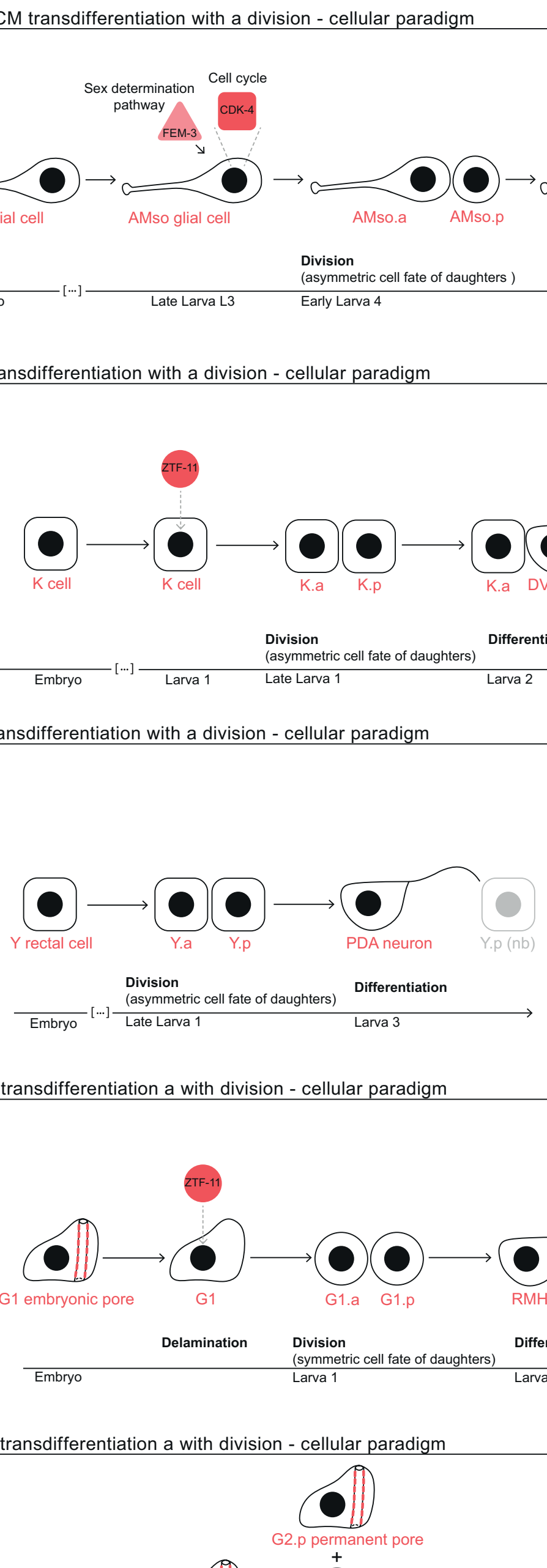

G1-to-RMH transdifferentiation a with division - cellular paradigm

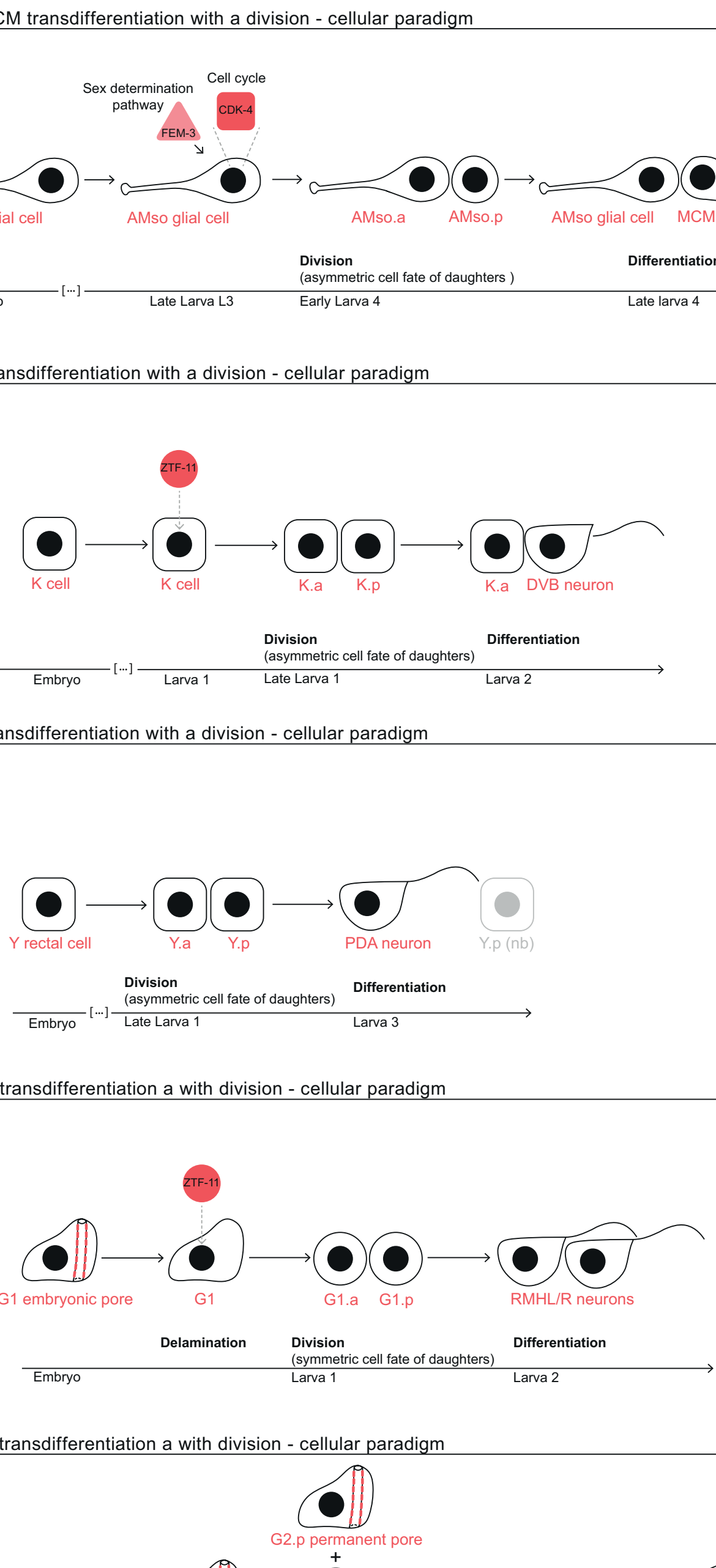

G2-to-RMF transdifferentiation a with division - cellular paradigm

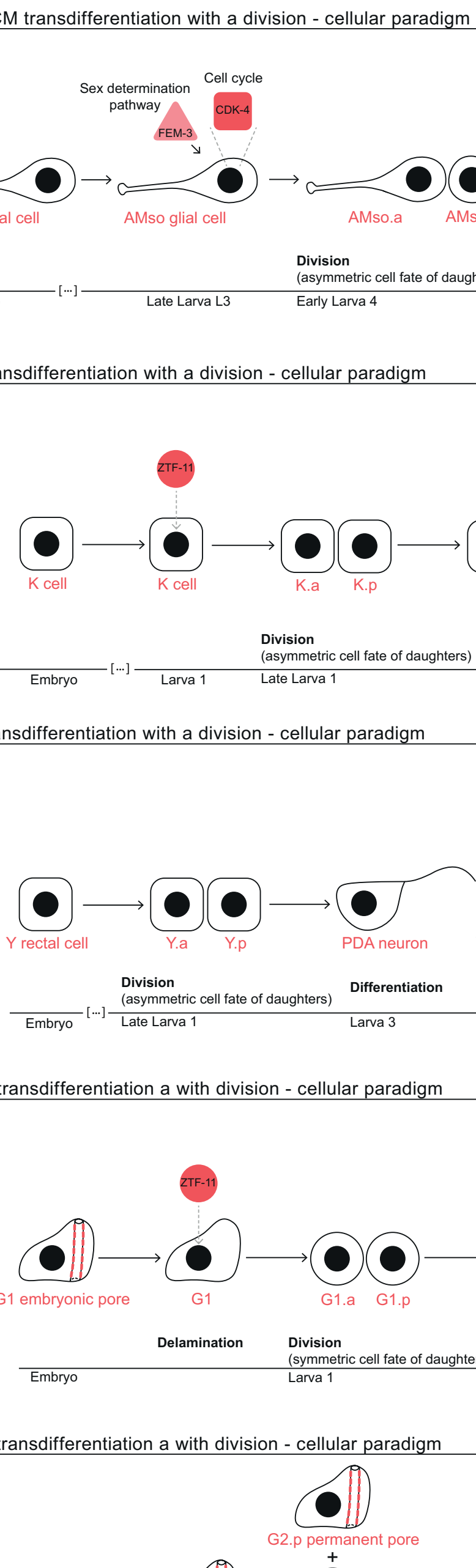

G2.p permanent pore

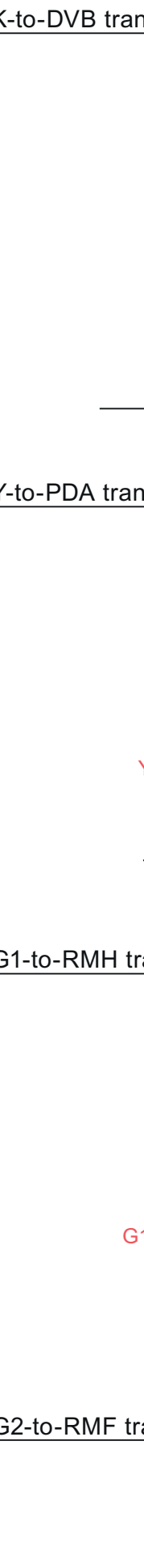

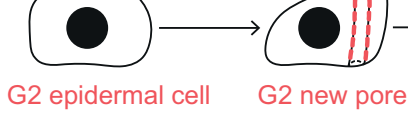

G2 epidermal cell

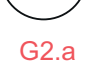

Pore replacement

Embryo Larva 1

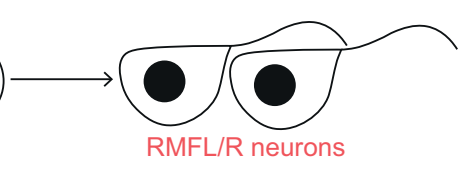

Differentiation Larva 2 Late larva 2 